\title{
الاعتداء على الحقوق المعنوية
}

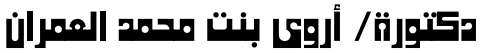

$$
\text { جامعة الإمام محمد بن سعة- كلية الشريعة الإسمدامية }
$$

\section{المقدمة}

إن الحمد لله نحمده ونستعينه ونستغفره ونعوذ بالله من شرور أنفسنا وسيئات

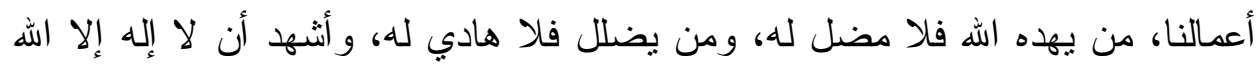

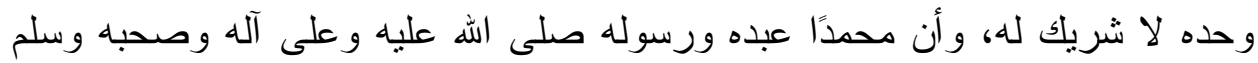

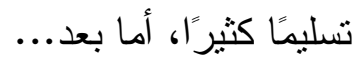

فان حب الثهرة و الظهور أمام الآخرين، داء قد ابتلي به كثير من الناس، فأر ادوا الوصول لغايات بسبل غير مشروعة وقد يكون ذللك بجهل منهم بعدم

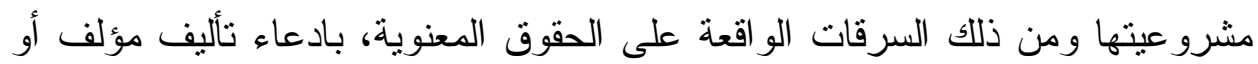

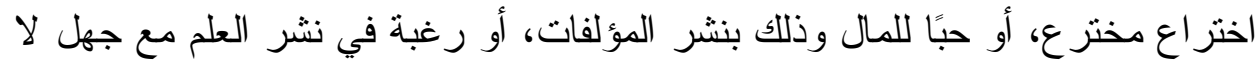
يتضدنه حق المؤلف مما يحرم الاعتداء عليه، وقد ساعد في ذلك التطور التقني الحديث وظهور وسائل النشر الحديثة، من هنا دعت الحاجة لبحث هذه المسألة وهي: (الاعتداء على الحقوق المعنوية). أسباب اختيار الموضوع وأهميته: -أن الحقوق المعنوية تقابل الحقوق المالية من حيث الأهمبة ووجوبية الهوبئ العناية بها. -أن دراسة هذه الحقوق من الأمور النازلة التي تحتاج لتجلية الحكم فيها وبحثنه. -مسيس الحاجة لار اسة المسائل المترنبة على الاعتداء على تلألك الحقوق. - إثر اء البحوث بمسائل معاصرة يحتاج إليها عموم الناس.

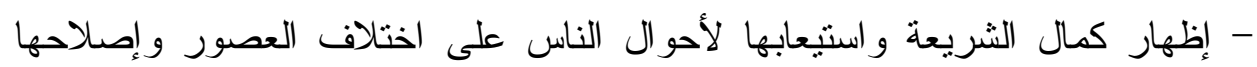
لمعاش الناس وحياتهم. -بيان ما يتصف به الفقه الإسلامي من القوة والسعة و الاستيعاب لمعطيات العصر وتقديمه الحلول التي تتحقق بها المصالح وتتدفع بها المضار . لإسله 
الار اسات السابقة:

بعد البحث في مو اقع التكثيف للرسائل العلمية والبحوث المحكمة وجدت بعض

الرسائل و البحوث التي قد يكون بينها وبين الموضوع بعض بعض النتابه، ومنها:

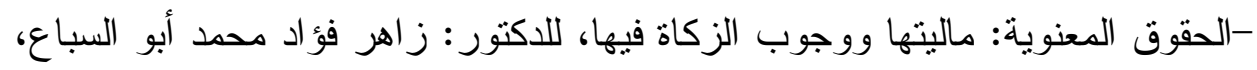

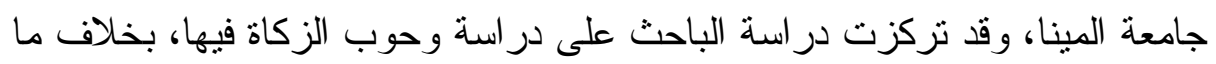
هو محل الدراسة من الاعتداء عليها. -الوجيز في حقوق الملكية الفكرية، المؤلف: حمداله محمد حمداله، وقد اهتم الباحث في بحثه بنوع من الحقوق المعنوية، ووعي صاحب الحق لمقيه بحقه.

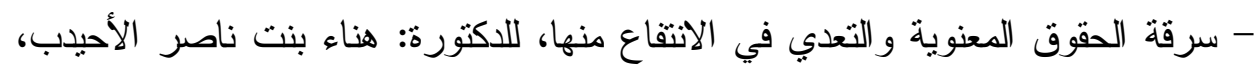

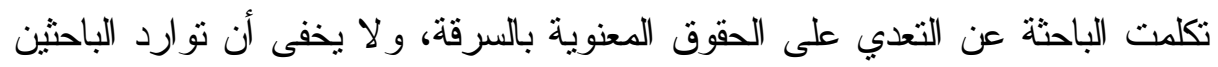

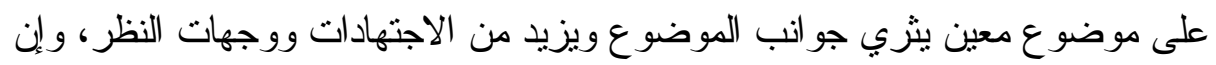
كان هناك تنابه في تأصيل الموضوع من حيث الجملة فهذا لا يخفى أن نفس الباحث

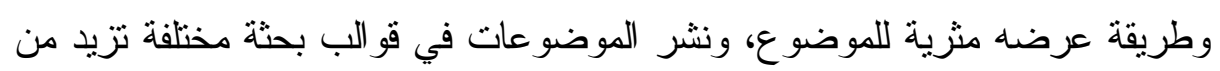
وعي المنلقي وقبوله.

-بيع الحقوق المعنوية بين الفقه والقانون ونطبيقاتها المعاصرة، د. محمد خير الفقيري، تبرز أهمية البحث في بيع الحقوق، فقد تركزت الدراسة على بيع الحقوق المعنوية.

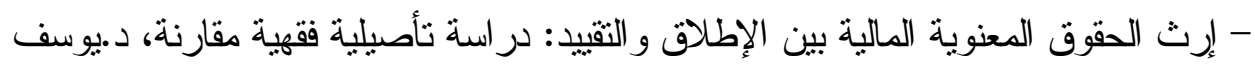

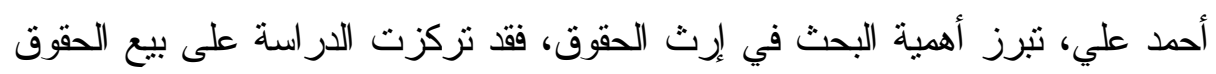
المعنوية.

-وقف الحقوق المعنوية من منظور اقتصادي إسلامي، د.إير اهيم الصمادي، موضوع البحث في الوقف، وجواز وقف الحقوق المعنوية و آلية وقفها.

سلكت في هذا البحث المنهج المتبع في دراسة المسائل الفقهية وهو كالآتي : منهج البحث:

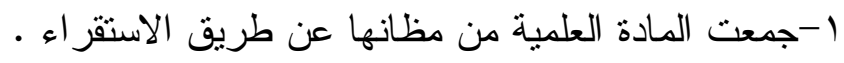

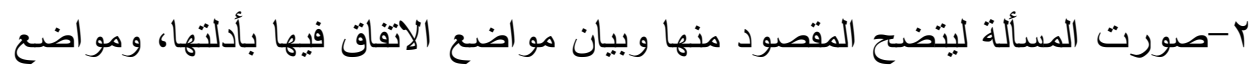

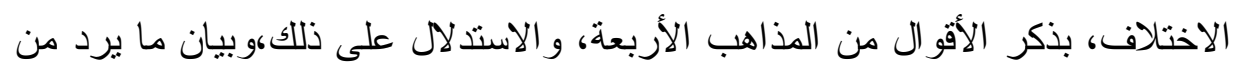

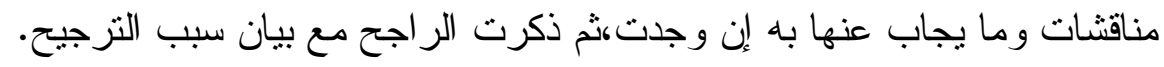


ب-وثقت من المصادر المعتبرة .

ع-عزوت الآيات إلى سور ها، وخرجت الأحاديث من مصادر ها وحكمت عليها.

0- ذكرت خاتمة ضمنتها خلاصة البحث، ونتائجه .

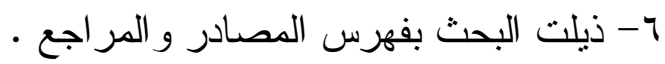

هذا وقد بذلت فيه جهدي فما كان فيه من حق وصواب فمن الله، وما كان غير

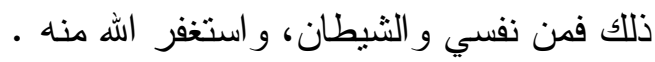

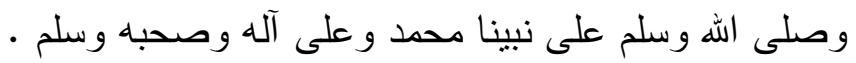

خطة البحث: - اث:

وقد انتظمت خطة البحث بعد المقدمة في خمسة مباحث:

المبحث الأول: تعريفات ألفاظ البحث. وفيه خمس مطالب:

المطلب الأول: تعريف السرقة لغةً و اصطلاحًا.

المطلب الثاني: تعريف الحق لغةً و اصطلاحًا.

المطلب الثالث: تعريف المعنوية.

المطلب الر ابع: المر اد بالحقوق المعنوية، و الألفاظ التي تطلق عليها.

المطلب الخامس: ركنا الحق المعنوي، و الفرق بينهما.

المبحث الثاني: التكيف الفقهي للحقوق المعنوية. وفيه ثنات مطالب:

المطلب الأول: تعريف المال لغةً واصطلاحًا.

المطلب الثاني: التكييف الفقهي للحقوق المعنوية.

المطلب الثالث: اعتبار الحق المعنوي.

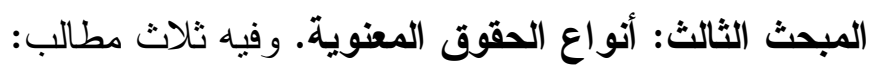

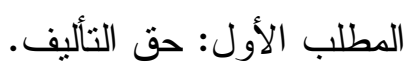

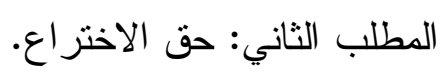

المطلب الثالث: حق الاسم التجاري. حق الاختر.

المبحث الرابع: صور سرقة الحقوق المعنوية، والتعدي في الاتفاع منها. وفيه ثناث مطالب:

المطلب الأول: صور سرقة حقوق التأليف و الاختر اع.

المطلب الثاني: صور سرقة الاسم التجاري. 


$$
\begin{aligned}
\text { المبحث الخامس: وفيه مطلبان: الثالث: السرقات الإكترونية. } &
\end{aligned}
$$

المطلب الأول: الجهود التي تسهم في حماية الحقوق المعنوية قبل الاعنداء

المطلب الثاني: عقوبة سرقة الحقوق المعنوية، و التعدي في الانتفاع منها.

$$
\begin{aligned}
& \text { الخاتمة: وفيها ذكر أهم نتائج البحث. } \\
& \text { ثبت المصادر و المر اجع. } \\
& \text { فهرس الموضوعات. }
\end{aligned}
$$

أسأل اله تعالى التوفيق والقبول، وما من صواب فمن الهه وما كان من خطأ

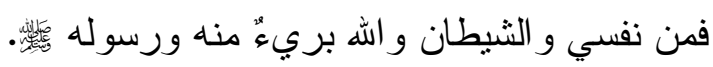




\section{المبحث الأول \\ التعريف بمصطلحات البحث}

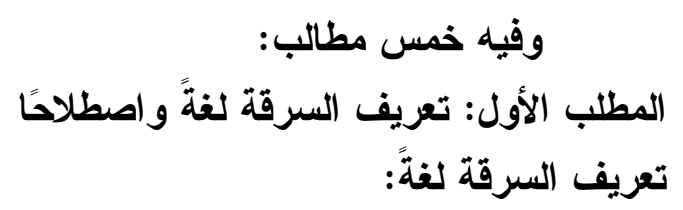

أصلها من (سرق)، السين والراء و القاف، أصل يدل على أخذ شيء في خفاء وستر ، يقال: سرق يسرق سرقة و المسروق.

و الاسم السرق و السرقة بكسر الر اء فيهما - و واسم الفاعل (سارق).

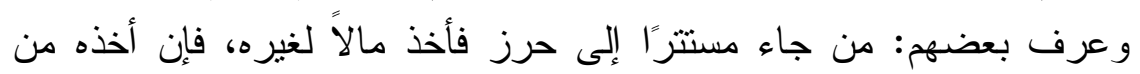

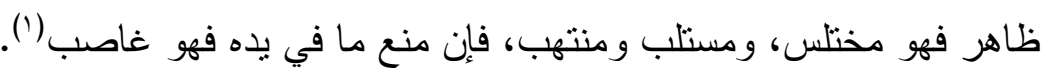
| (صطلاحًا:

عرفها الحنفية بأنها: أخذ مال الغير على سبيل الخفية نصابًا محرزًا للتمول

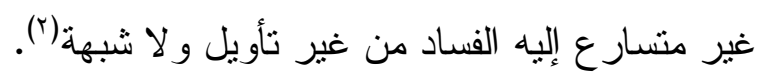

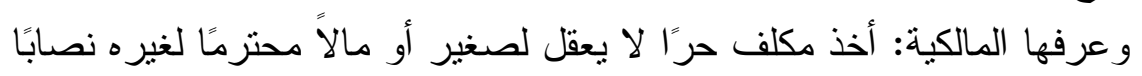

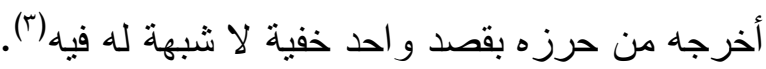

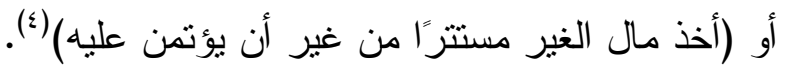

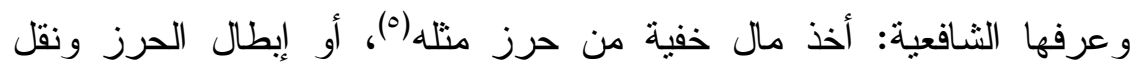

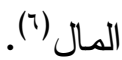

وعرفها الحنابلة: أخذ المال على وجه الخفية و الاستتار (vأ.

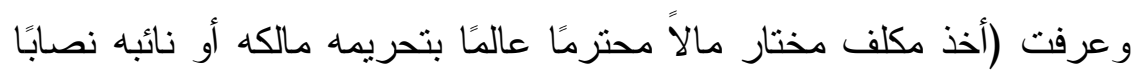

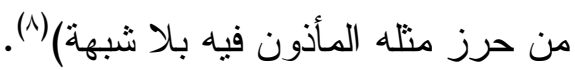

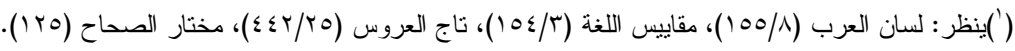

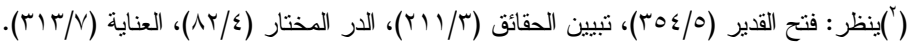

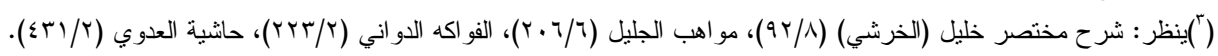

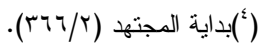

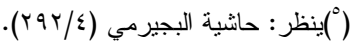

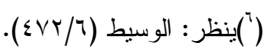

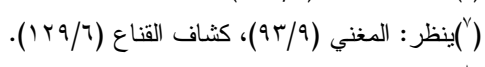

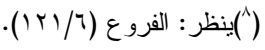


المطلب الثاني: تعريف الحقوق لغةً واصطلاحًا لغةً:

مفردها (حق)، الحاء القاف أصل و احد وهو بدل على إحكام الثيء وصحته

فالحق نقيض الباطل، يقال حق الثيء: وجنب.

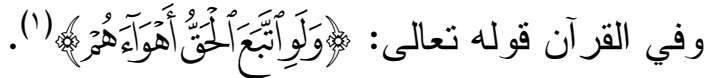

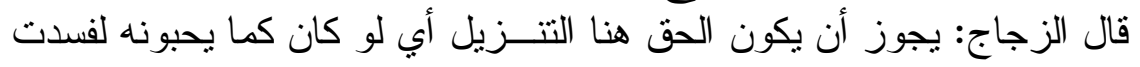

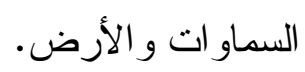

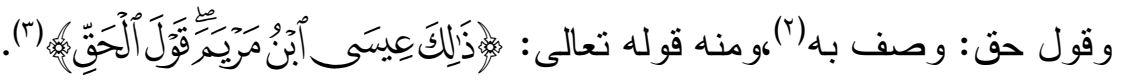

اصطلاحًا:

عرفه الأستاذ مصطفى الزرقا بأنه: (اختصاص يقرر به الثرع سلطة أو

تكليفًا) (ع)

المطلب الثالث: تعريف المعنوية (نسبة إلى المعنى) لغةةً:

ما يدل على اللفظ وجمعه معان.

و المعاني ما للإنسان من الصفات المحمودة، و المعنوي خلاف المادي(0)، وهذان مذان

هو المقصود من المعنوية في (الحقوق المدنية).

أي الحقوق غير المادية(؟).

المطلب الرابع: المعنى الإجمالي للحقوق المعنوية والألفاظ التي تطلق عليها

لغةًة:

الحقوق المعنوية هي سلطة لشخص على شيء غير مادي، سواء أكان نتاجًا

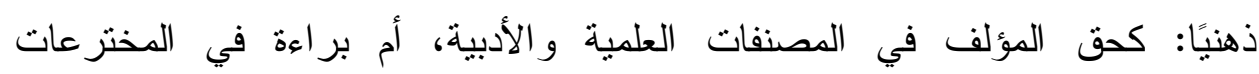

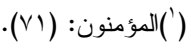

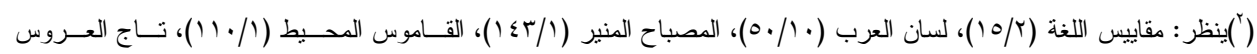

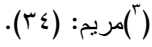

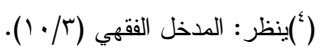

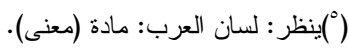

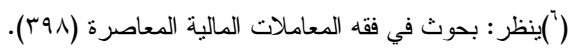


الصناعية، أم ثمرة لنشاط تجاري يقوم به التاجر لجلب العملاء كما في الاسم التجاري

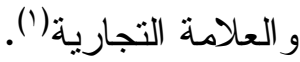
الألفاظ التي تطلق على الحقوق المعنوية: 1- الملكية الأدبية و الفنية و الصناعية.

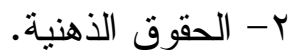
ب- الحقوق التي تزد على أمو ال غير مادية. ع - الحقوق المتعلقة بالعملاء.

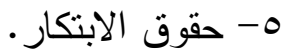

7- الملكية المعنوية.

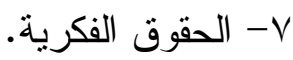
1- حق الإبداع. 9- حقوق الإنتاج العلمي.

• 1 - ملكية التأليف (r).

المطلب الخامس: ركنا الدق المعنوي، والفرق بينهما الحقوق المعنوية في جملتها لها ركنان: الركن الأول: الحق الأدبي.

ويعبر عنه بالحق المعنوي، ويعتبر أحد الجوانب الهامة في الملكية الفردية و هو منصب على حماية صاحب الحق من مؤلف أو مخترع وكذلك حماية الحق ذاته، وبهذا المعنى فهو ينطوي على وجهين:

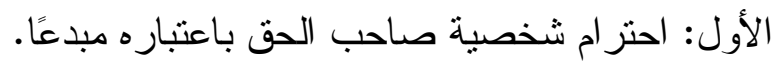

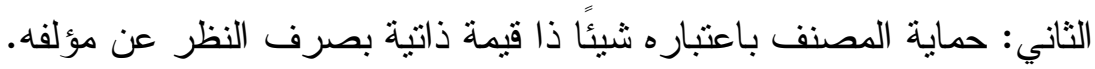

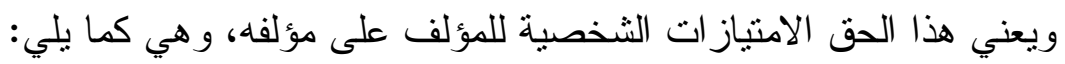
1- نشر المصنف باسمه أو باسم مستعار ، أو دون اسم.

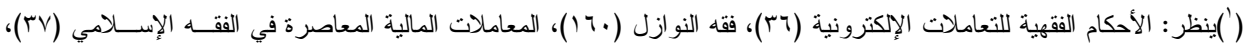

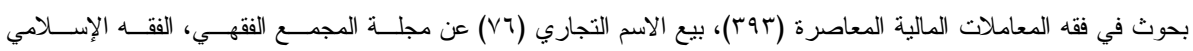


ץ- الاعتر اض على أي تعدٍ على مصنفه، ومنع أي حذف، أو تغيير أو إضافة أو تحريف أو تشويه.

ץ- أبوته على مصنفه باستمرار نسبته إليه، فليس له حق التتازل عن صفته التأليفية

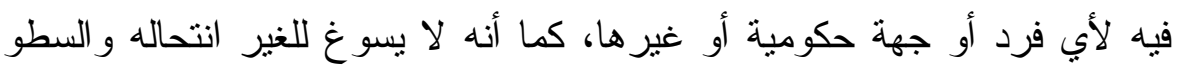
عليه، فله ولورثثه حق دفع الاعتداء عليه.

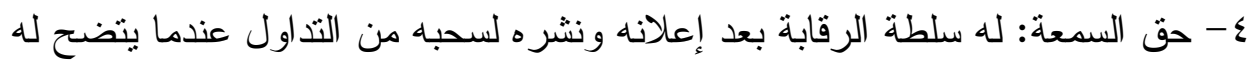

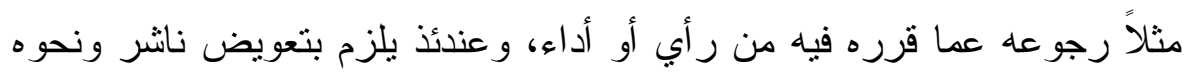

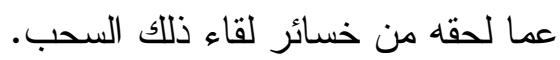
0- سلطة التصحيح لما فيه من تطبيعات عند إر ادة الناثر إعادة النشر . 7- استمر ار هذه الحقوق له مدة حياته فلا تسقط بالتقادم أو بالوفاة.

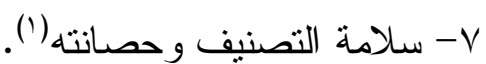
الركن الثاني: الحق المادي.

وتنهى بالحقوق الاقتصادية أو الحقوق التجارية أو الحقوق المالية، وهي بمثابة الامتيازات المالية للمؤلف لقاء مؤلفه، وهي حق عيني أصلي مالي منقول وحق قسيم للحق

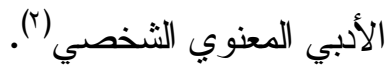
وير اد بالحق المادي: إعطاء كل صاحب إنتاج ذهني حق احتكار واستغلال هذا

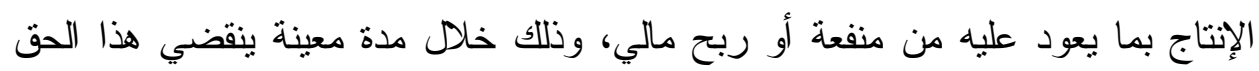
بفواتها، وإن لصاحب الابتكار استثماره لنفسه، و السماح لغير باستثماره، أو جعله مباحًا للجميع للاستفادة منه (r).

ومن الحقوق المالية للمؤلف التي يجوز له أو لمن يفوضه ممارستها ما يلي:

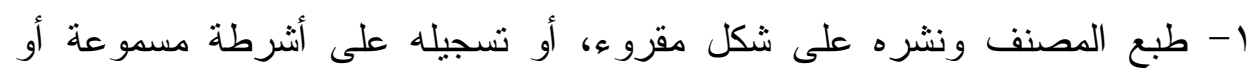
مرئية أو اسطو انات مدمجة أو ذاكرة إلكترونية. r- نرجمة المصنف إلى لغات أخرى. 


\section{r- نقل المصنف إلى الجمهور بأي وسيلة ممكنة('). الفرق بين الركن الأدبي والركن المادي:}

ا- اختلاف المحل: ذلك أن الحق المادي محله أكيد احتكار المؤلف فهو يمثل قيمة الرن مالية، أما الحق الأدبي فيهدف إلى حماية شخصية المؤلف.

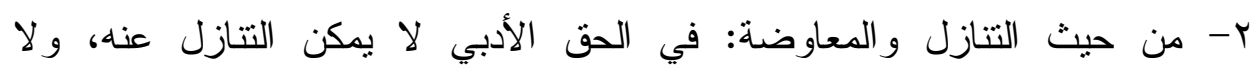

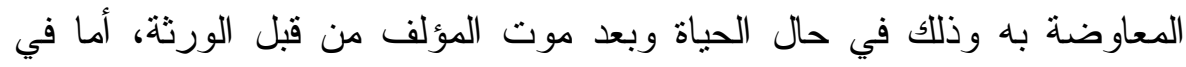
الحق المادي فيمكن التتازل عنه و المعاوضة به به.

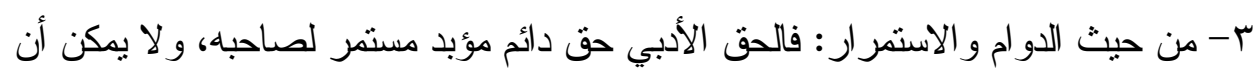
ينتقل لغيره حتى ورثثه من بعده، بخلاف الحق المالي فيمكن انتقاله؛ كانتقاله لورثثه من ولن الأن

بعده (r)

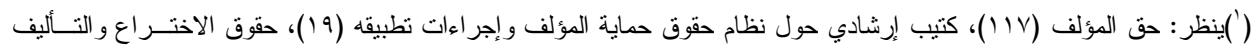

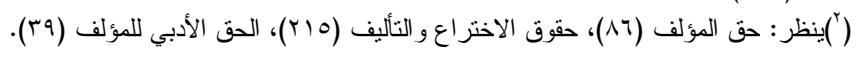




\section{المبحث الثاني \\ التكييف الفقهي للحقوق المعنوية}

\section{وفيه ثلاث مطالب: \\ المطلب الأول: تعريف المال لغةً و واصطلاحًا

كل ما يملك من جميع الأثياء فهو مال، يقال: مال يمول مولاً إذا صار ذا لها

$$
\text { مال، ورجلٌ مالٌ أي كثير المال، و الجمع: أموال ('). }
$$

اصطلاحًا:

عرف بتعريفات كثيرة، لعل أرجحها ما عرفه به الحنابلة(؟)،: ما فيه منفعة

$$
\text { مباحة لغير حاجة أو ضرورة. }
$$

(ما فيه منفعة): قيد خرج برو به ما لا منفعة فيه كبعض الحشر ات.

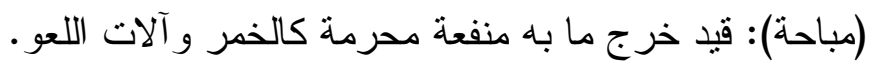

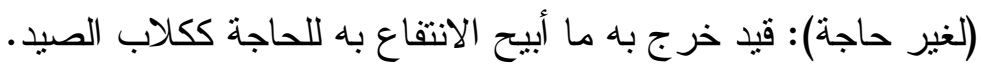

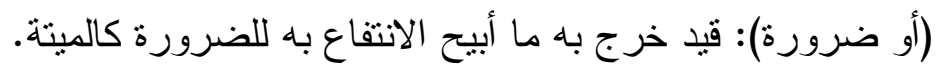

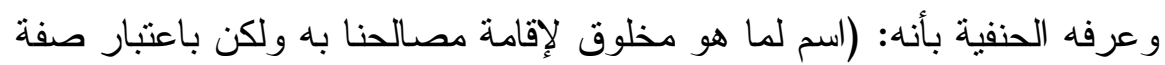

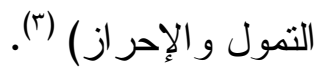

المطلب الثاني: التكيف الفقهي للحقوق المعنوية

إن التكييف الثرعي للحقوق المعنوية مبني على اعتبار الحقوق المعنوية

أمو الاً أم لا؟

و هذه المسألة مبنية على اختلاف العلماء كرحمه الله- في اعتبار المنافع

أمو الاً.

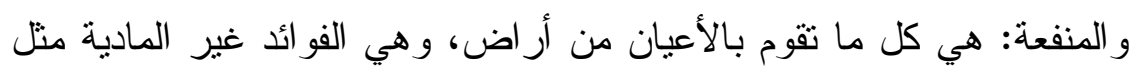

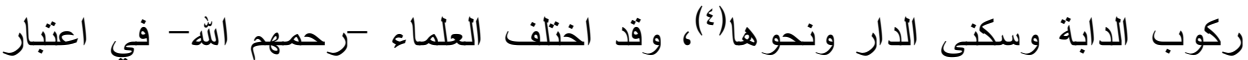

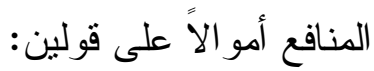

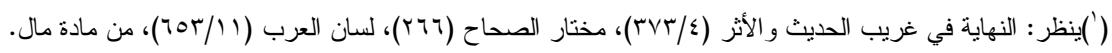

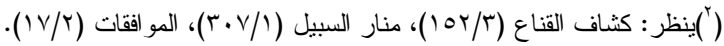

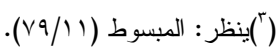

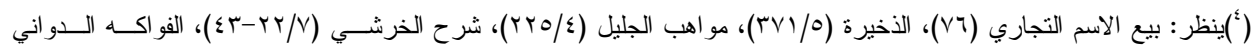


اعتبار المنافع أمو الاً منقومة، يقع عليها البيع وتجوز المعاوضة بها، وهذا هو قول

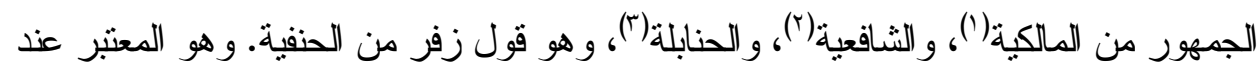

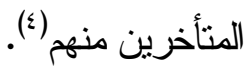

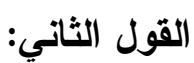

أن المنافع لا تعتبر أموالاً، وهذا هو قول الحنفية عدازفر (ْ).

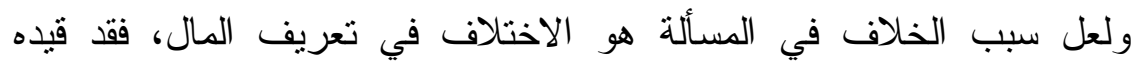

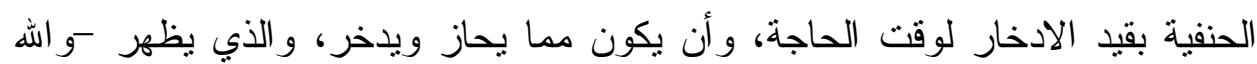

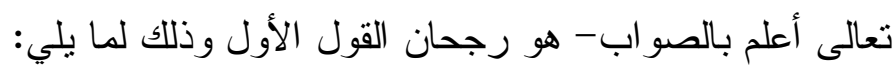

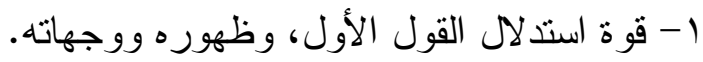
حيث استدلوا من القر آن و السنة:

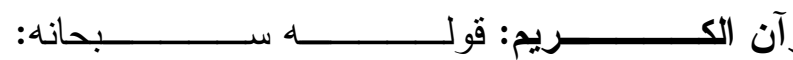

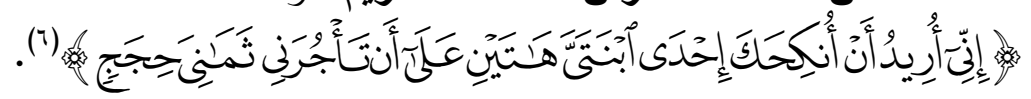

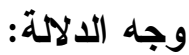

فيه جواز كون الإجارة صداقًا ولو كانت المصدوقة المستاجرة فتقوم المنفعة من الإجارة مقام الصداق، ومعلوم أن الصداق هو العوض المستحق في عقد النكاح(") فأقام المنفعة من الإنة

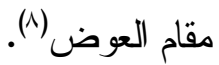

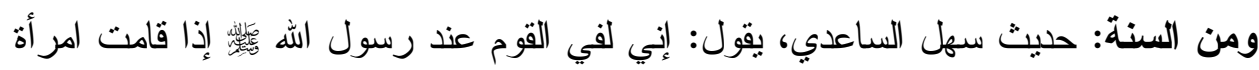

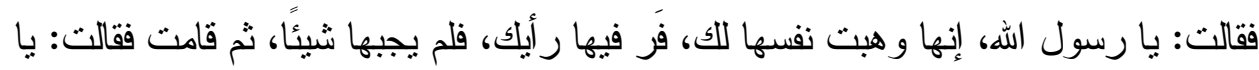

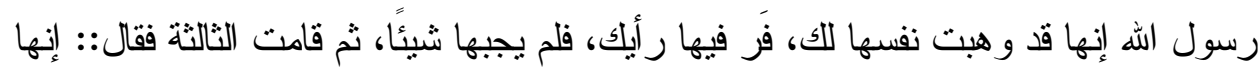

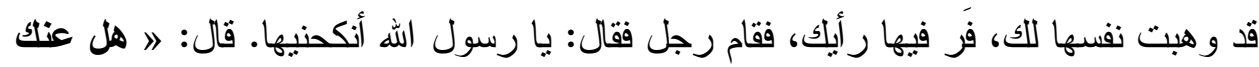

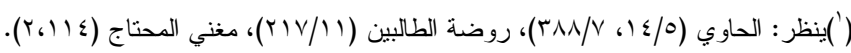

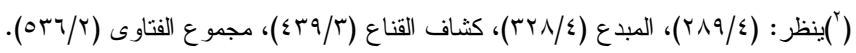

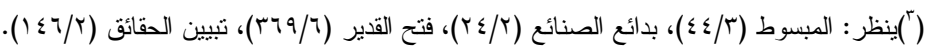

$$
\begin{aligned}
& \text { ( (') (1) }
\end{aligned}
$$

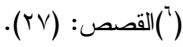

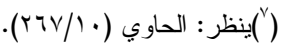

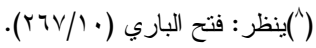


من شيع؟ « قال: لا، قال: 》 اذهب فاطلب ولو خاتمًا من حليذ «، فذهب وطلب، ثم جاء

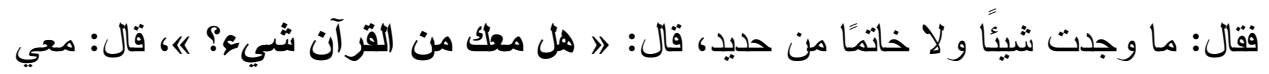

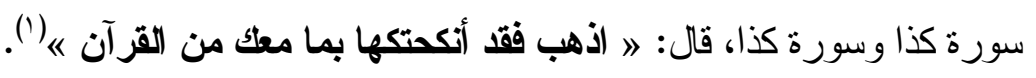

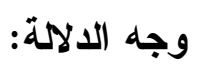

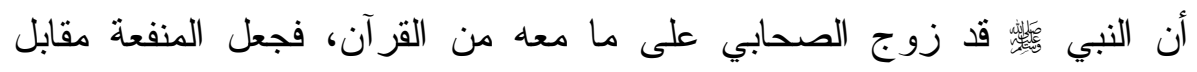

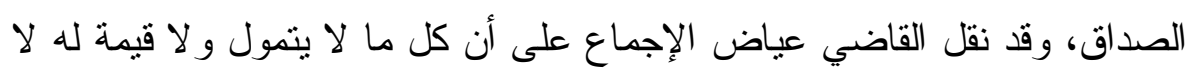

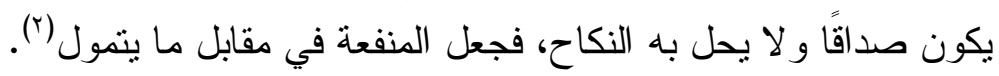

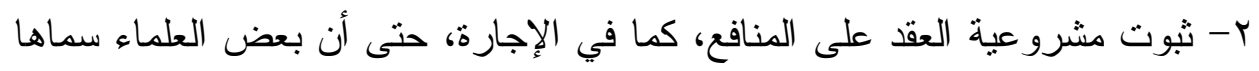

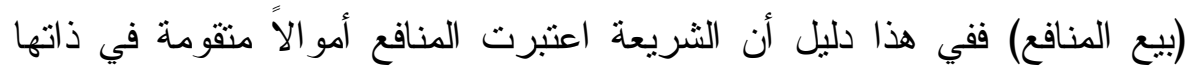

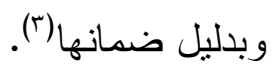

ץ- أن العرف جرى على اعتبار المنافع أموالاً، بيانه: أنه أقر وقوع العقود عليها،

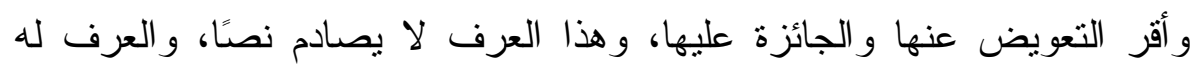

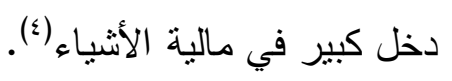

ع- أن المنافع أصل للوسائل المادية من سيارة وطائرة، ونحوها، فلا بد من اعثبار

الأصل وأن له صفة المالية أن.

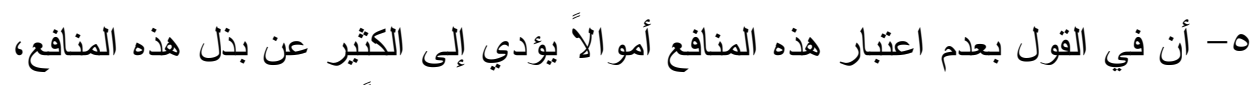

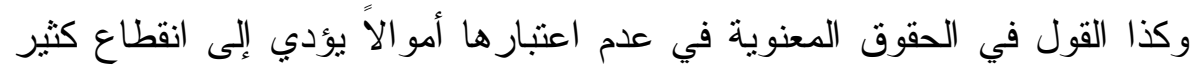

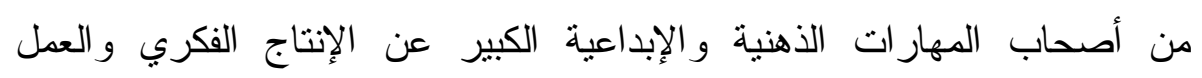

الإبداعي حيث برى أن ما يجتهد فيه لا يملكه(آ).

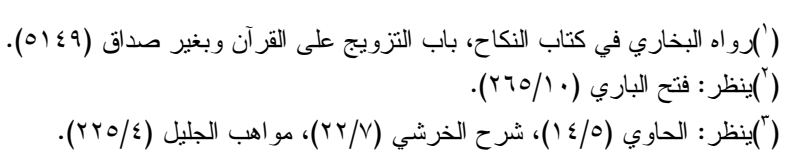

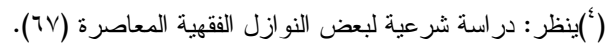

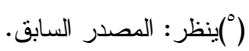

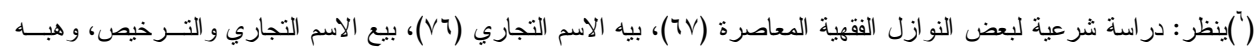

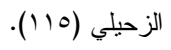


7- أن فقهاء الحنفية أصبحو ا يذهبون إلى القول الأول وهو قول زفر منهم -وهو القول بماليتها- كما يظهر في رد المحتار (قوله بيع حظوظ الأئمة... بيع حظ بمعنى لهونى النصيب المرتب له من الموقوف، أي فإنه يجوز بيعه)(').

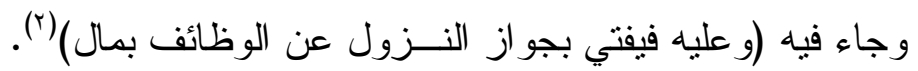

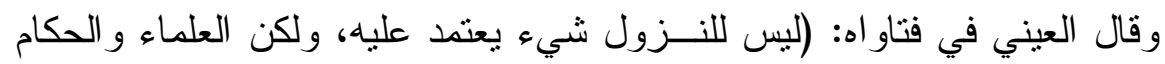

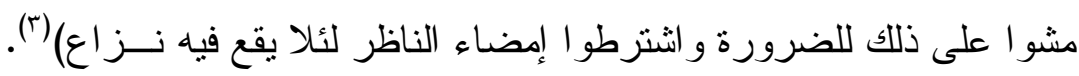
المطلب الثالث: اعتبار الحق المعنوي وفيه مسألنان:

الأولى: المرجع في اعتبار الحق المعنوي. أن اعتبار أي حق من الحقوق لا بد أن يكون من منشأ هذا الحق الحق، و الحقوق لها

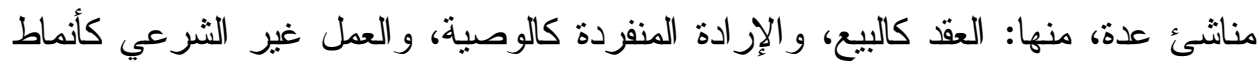

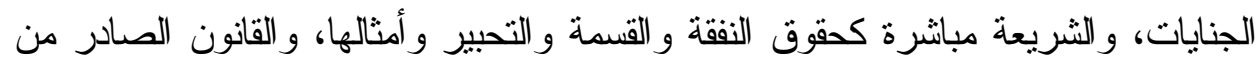

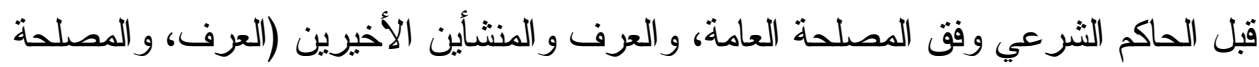

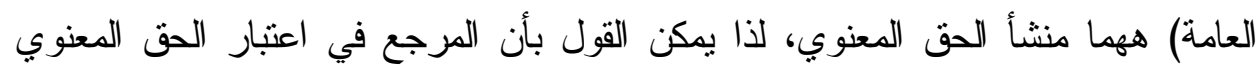

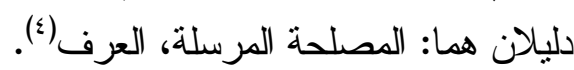

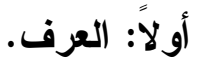

تتقسم الحقوق من حيث مرجعيتها إلى قسمين:

1- الحقوق الثرعية: وهي التي تثبت من قبل الثارع، و لا مدخل للقياس فيها.

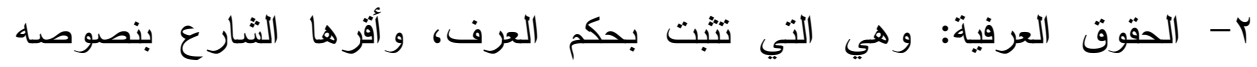
العامة) (0) و الحقوق المعنوية مندرجة تحت القسم الثاني. 
و العرف: هو مجموع القو اعد التي تتشأ من درج الناس عليها، يتو ارثونها جيلاً بعد

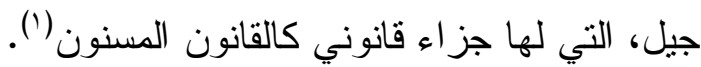

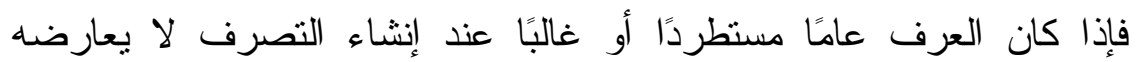

تصريح بخلاف و لا يخالف نصيًا شرعيًا من كتاب أو سنة أصبح دليلاً قائمًا بذاته (؟).

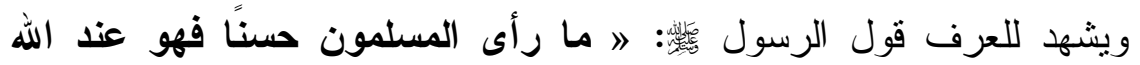

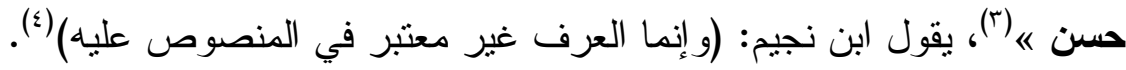
هذا العرف بمعناه العام، وقد يخصص العرف إنماف بحرفب ما بتعارف عليه زمرة في نفس المجال منل العرف القانوني ويكون هو المصدر الثاني بعد النص القانوني وكذلك العرف التجاري و العرف الأدبي وهو ما يكون بين الأدباء وهكذا. ثانيًا: المصلحة المرسلة. إن هذه الحقوق معتبرة شرعًا، وذللك لمكانتها الهامة في حياة الناس،وهذه من النها

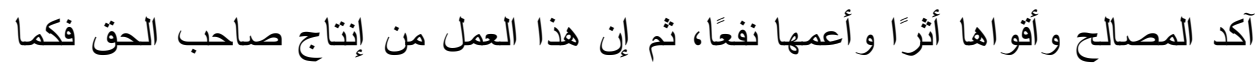

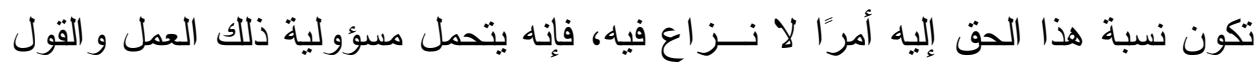

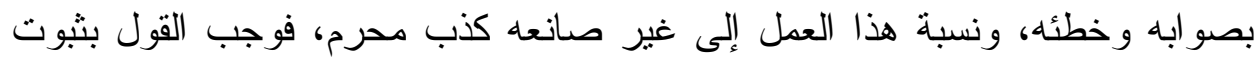

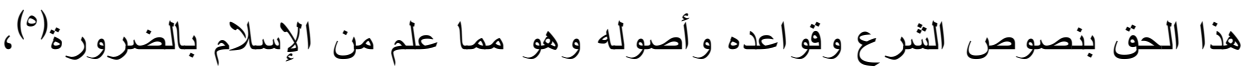
ويتجلى هذا في عدة مظاهر لاى المؤلفين، ومنها: ا - الأمانة العملية و العلمية في الأداء و التوثيق. צ- ب أحريم الكذب و التدليس. ع - تحريم السرقة و الانتحال. ه- ذكر المصادر التي يعتمدها المؤلف في تأليفه(؟).

(') ('بنظر : بيه الاسم التجاري -من مجلة المجمع الفتهي - (VT).

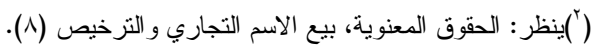

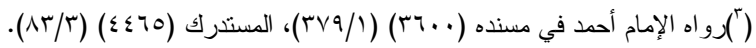

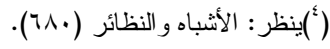

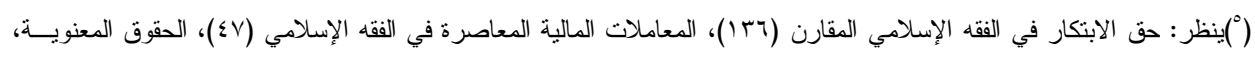

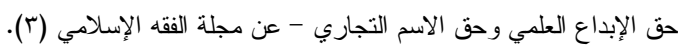
(")يظر : فقه النوازل (r/ (170). 
المسألة الثانية: وقت اعتبار الحق المعنوي.

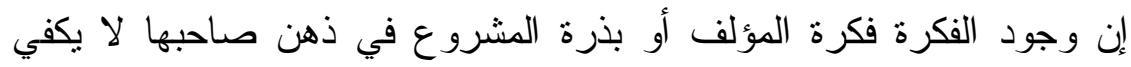

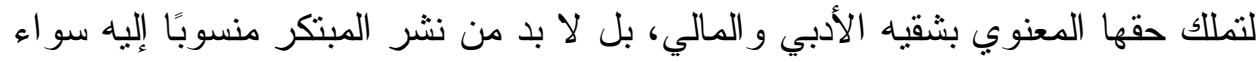
بذكر اسمه على المصنف أو بأي طريقة أخرى ما لم يقم دليل على نفيه(').

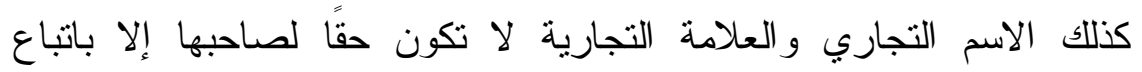

القانون المتبع في تسجيلها وجعلها من حقوق صاحبها التي يجب حمايتها (). أما بالنسبة لانتهاء وقت اعتبار الحق المعنوي، فقد جاء في مدة حماية هذهاه الحقوق بأن تكون بوجه عام مدة حياة المؤلف ولمدة خمسين سنة بعدها، و استنتى النظام من ذللك الأعمال التي تتشرها الثخصيات المعنوية والأعمال السمعية و البصرية

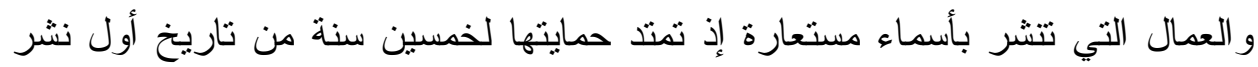

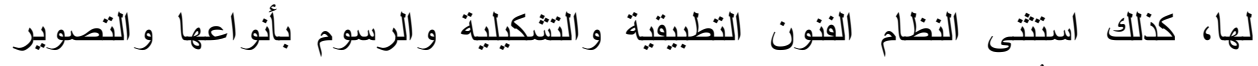
الفوتوغر افي فتحمى لمدة خمس وعشرين سنة من تاريخ أول نشر لها، وبالنظر إلى ونى

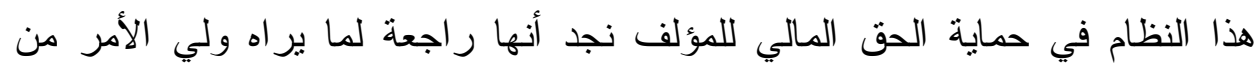

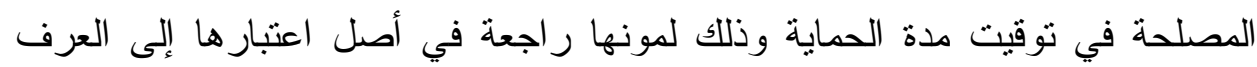
و المصلحة، فكذلك في وقت انتهاء مدة حمايتهاب(ّ).

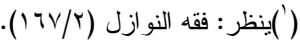

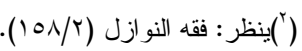

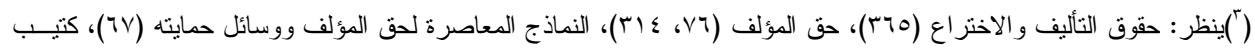
إرشادي حول حماية حقوق المؤلف (rY). 


\section{المبحث الثالث \\ أنواع الحقوق المالية}

يمكن قصر الحقوق المعنوية على ثلاثة أنواع، كما نهج ذلك أكثر العلماء ولتداخل بعضها داخل بعض، و هي:

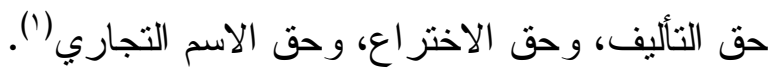
وسأجملها في المطالب الآتية: المطلب الأول: حق التأليف أولاً: تعريف حق التأليف لغةًة. الهمزة و اللام و الفاء أصل و احد يدل على انضمام الثيء إلى الثيء، وكل شيء ضممت بعضه إلى بعض فقد ألفته تأليفًا (؟). ثانيًا: حق التأليف.

هو ما يثبت للعالم أو المؤلف من اختصاص شرعي بمؤلفه يمكنه من نسبته

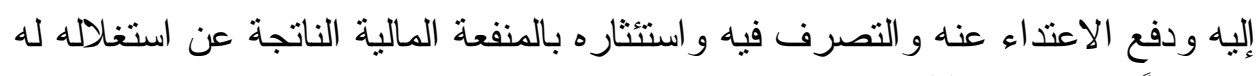

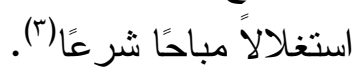

فهو بهذا التعريف لا يخرج عن المعنى اللغوي للتأليف، فينطوي على كل عمل دل دانل

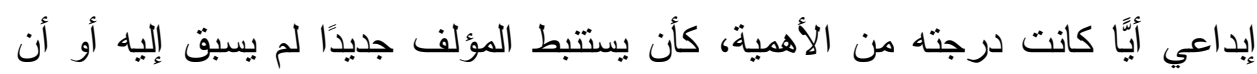
يكون تطويرًا لعمل علمي عن طريق تفسيره و التفصيل فيه أو تصحيح أخطائه أو أو أولئه

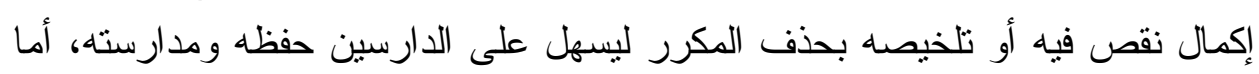

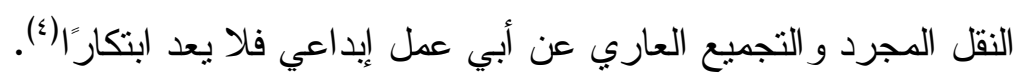

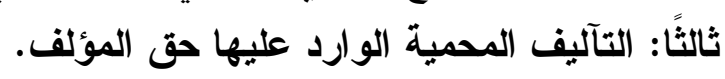
و هي نوعين بالتتبع:

1- المحرزات: وهي المؤلفات في أي من العلوم كالتقسير و الحديث و الفقه و أصولها،

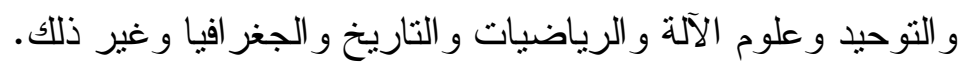

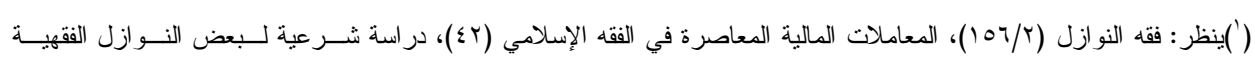

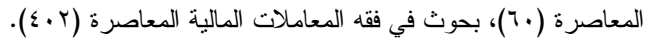

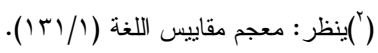

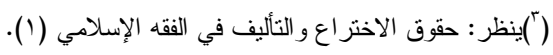

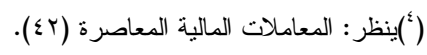


r- الثفويات: كالخطب و المحاضر ات و المو اعظ و الندو ات وما جرى مجرى ذلك مما

$$
\text { يلقى شفاهًا. }
$$

وتتثمل النوعين كل ما كان مكتوبًا بواسطة برامج الحاسب الآلي، أو مكتوبًا

في أثرطة أو اسطو انات رفيعة تقر أ بو اسطة الحاسب الآلي.

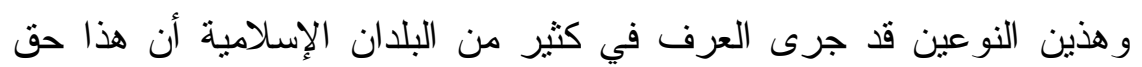

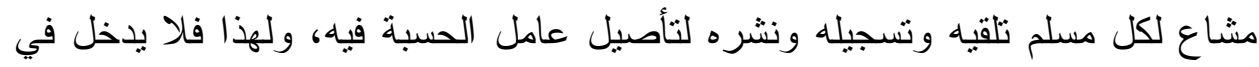

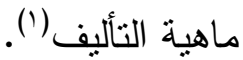

رابعًا: الحقوق الواردة على المؤلفات.

يرد على المؤلفات حقان:

الأول: حق خاص: وهو حق للمؤلف نفسه، ومن أتى من طريقه وهو ما اصطلح عليه بالحقوق الأدبية و المالية، ويشمل حق المؤلف في تقرير نشر مصنفه، وفي نسبته إليه، وحقه في تعديل مصنفه، وحقه في سحب مصنفه من التداول، وحقه ولانه في دفع الاعتداء على مصنفه، وحقه في الاستثمار لنفسه أو لغيره.

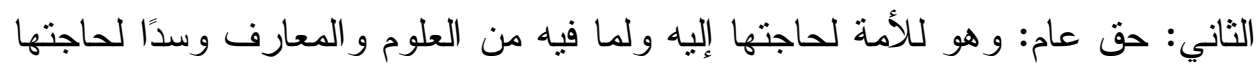

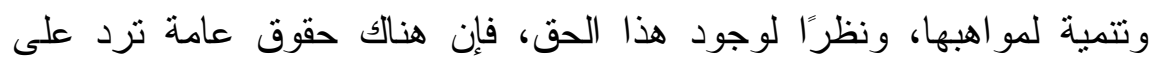

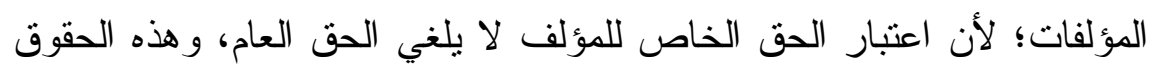

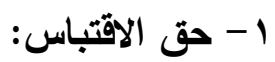

من أعظم منافع و إيجابيات التأليف الاقتباس، فهو انتفاع شرعي وذلك باتخاذ

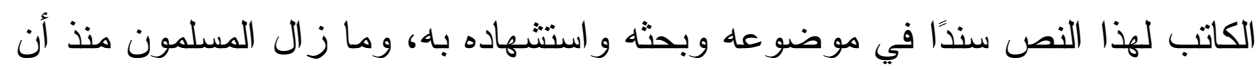

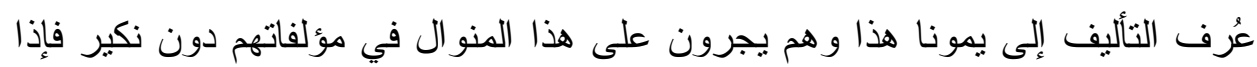

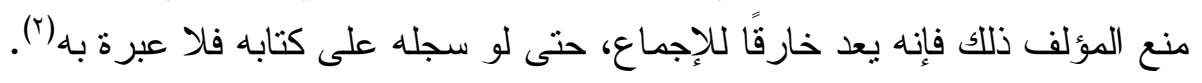
ولكن ليس هذا على إطلاقه بل له شروط منها:

1- أن يكون الاقتباس بالقدر الذي تبرره الغاية المر اد تحقيقها. r- أن يكون الاقتباس بهد الاستعمال لغايات حسنة. 
r- أن يكون المصنف الذي نقلت عنه الفقرات المقتبسة قد وضع مؤلفه في متتاول الجمهور بصورة مشروعة.

ع - أن يذكر في حال الاقتباس المصدر المصنف الذي اقتبس منه، و اسم المؤلف.

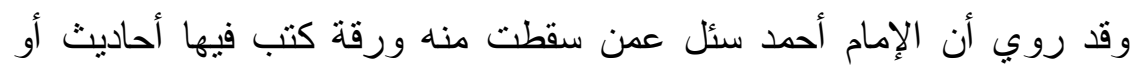

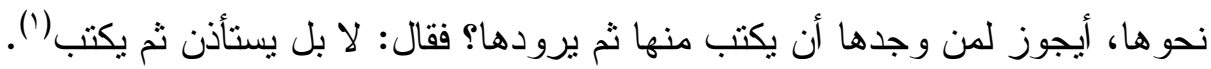

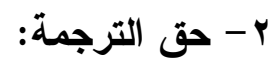

وهي نقل المؤلَّف من لغة إلى لغة أخرى، وهذا مقصور في أمرين: الأول: مدة أحقية صاحب الكتاب الأصل في المطالبة بحماية حقه مقابل قيام غيره بنزرجنه إلى لغة أخرى.

الثاني: مدى احتفاظ المتزجم بحقوق الترجمة باعتبار ما يبذله المترجم من جهود

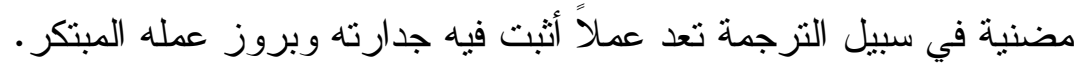

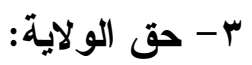

و هو حق الدولة في إجبار المؤلف على نشر مؤلفه عند ممانعته من نشره حيال قيام

الحاجة إليه( آن.

المطلب الثاني: حق الاختراع

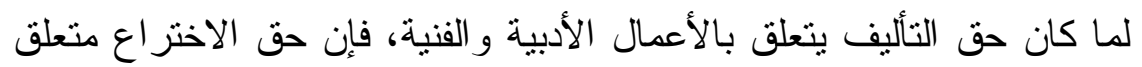

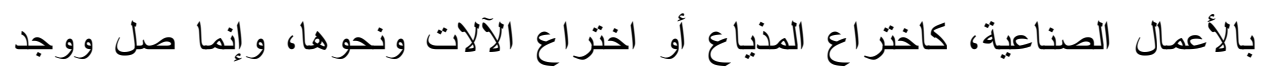
نتيجة التقدم الصناعي وتغير أساليب الحياة.

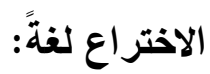

من خرع الثيء خرعًا أو اختر اعًا، بمعنى شقه و أبدعه و أنشأه().

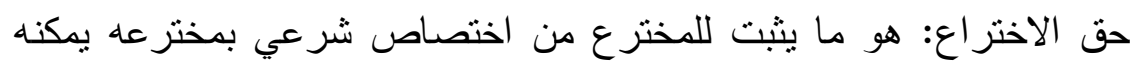

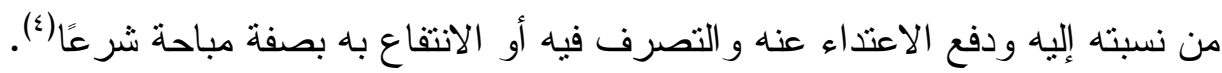

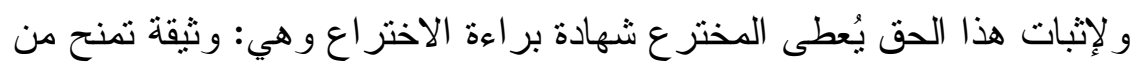
طرف دائرة رسمية أو من مكتب عامل باسم مجموعة من الأقطار بناء على ذللك،

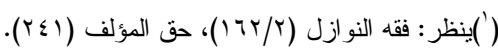

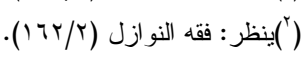

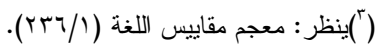

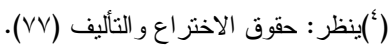


ويترتب على هذه الثهادة الرسمية حق من منحت له في استخدام الاختر اع المعين فيها و أعماله و التتازل عنه بالبيع و استنير اده ('). و على هذا فهي تمنح المخترع حقوقًا منها:

1- حق استغلال المخترع لاختر اعه و استغلال الورثة له بعد وفاته بمدة معينة.

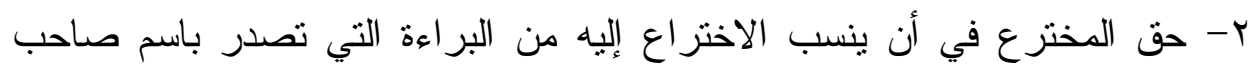

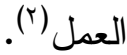
المطلب الثالث: الاسم التجاري وهو الاسم الذي يستخدمه التاجر الفرد أو الثركة التجارية لتمبيز المنشأة التجارية التي يباشر استغلالها. أو يقال: الاسم الذي غدا عنو انًا على محل تجاري نال شهرة مع الزمن بحيث تتجسد هذه الثهرة في الاسم المعلن عليه. كذلك يطلق الاسم التجاري وير اد به العلامة التجارية.

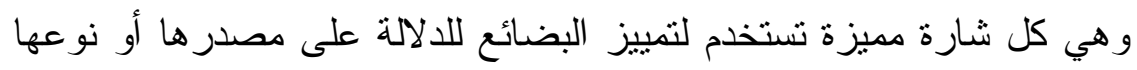

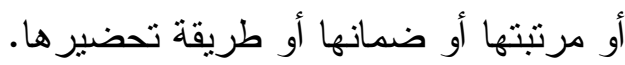
فالعلامة التجارية تستخدم لتمبيز البضائع و المنتجات، أما الاسم فيميز المنشأه التجارية ذاتها عن نظائر هاب(r). و على هذا فالاسم التجاري يشتمل على المضامين الآتية: 1- الثعار التجاري للسلعة أو العلامة التجارية (الماركة المسجلة). r- العنوان التجاري الخاص بمحل تجاري نال شهرة مع الزمن.

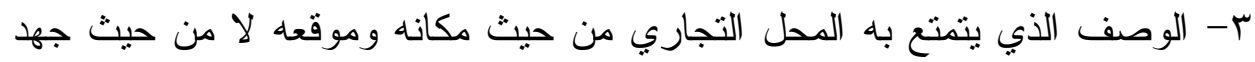

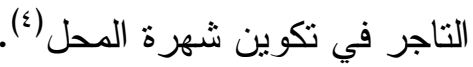

(') (')يظر : المعاملات المالية المعاصرة (0.0).

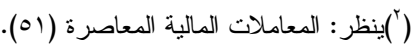




\section{المبحث الرابع}

\section{صور سرقة الحقوق المعنوية، والتعدي في الاتتفاع منها} وفيه ثلاث مطالب:

المطلب الأول: صور سرقة حقوق التأليف والاختراع لتصور هذه الصور لا بد من التأكيد على الحقوق السابقة وهي الحق الخاص

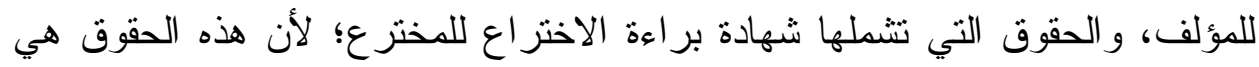
التي ستقع عليها السرقة، ومن صور السرقات الواردة عليها:

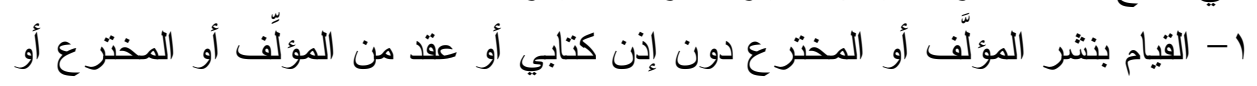
من ورثثه أو ممن يمثلهم نظامًا. r- نشر المؤلف أو المختز ع مع ادعاء ملكيته.

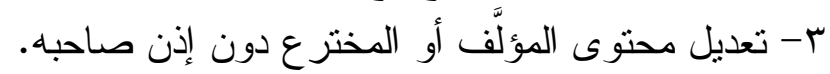

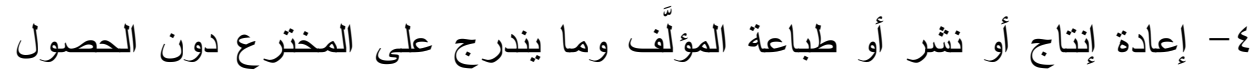
على مو افقة خطية من صاحب الحق. ه- الاستخدام التجاري للمؤلَّف أو المخترع بطرق فئ غير نظامية، منل الثقاط البر امج الإذاعية المشفرة. צ- نسخ أو تصوير جزء من المؤلف أو مجموعة مؤلفات دون الحصول على موافقة خطية من أصحاب الحقوق، ويستثى من ذلك: أ- نسخ الكتاب للاستعمال الثخصي.

ب- الاسنتهاد بفقرات من مصنف منشور في مصنف آخر، بشرط أن يكون الاسنتهاد

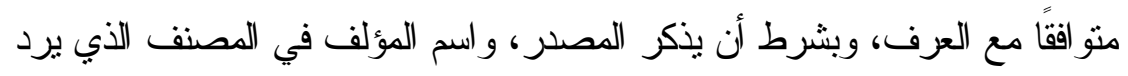
فيه الاستشهاد. جـ - الاستعانة بالمصنف للأغر اض التعليمية على سبيل الإيضاح. د- نقل مقتطفات قصيرة من مصنفات سبق نشرها إلى الكتب المدرسية المعدة

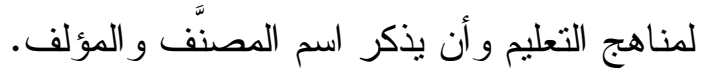
- V استير اد المصنفات المزورة أو المقلدة أو المنسوخة. 
^- الاحتفاظ بمصنفات غبر أصلية في المنشأة التجارية أو المستودع أو غير ذلك من

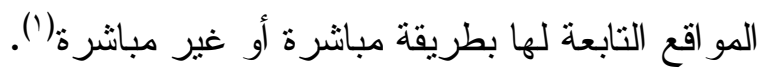
المطلب الثاني: صور سرقة الاسم التجاري لئانيا

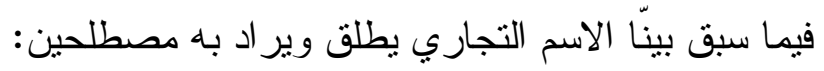

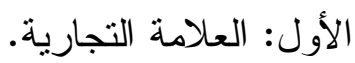

الثاني: العنوان التجاري الخاص بعمل تجاري نال شهرة مع الزمن. ومن صور سرقة الاسم التجاري:

1- سرقة العلامة التجارية: مما انتشر وعم في المجتمعات تقليد العلامات التجارية، أو

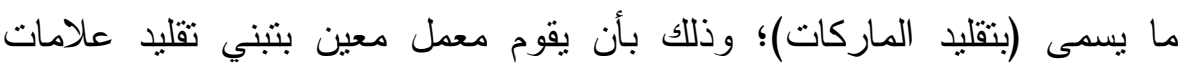
تجارية معينة ذات اسم مميز وسعر عال، ويقوم ببيعها على العملاء، وقد يكون

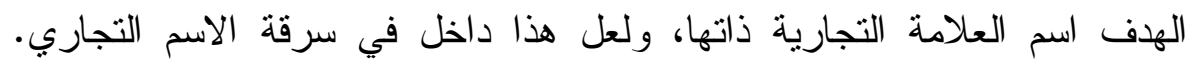
وهؤلاء حال بيعهم لتلاك السلع الدقلدة على العملاء بين حالين:

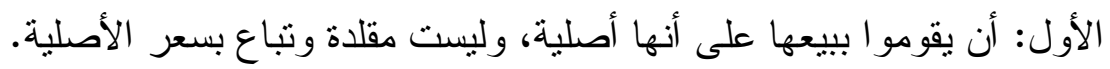

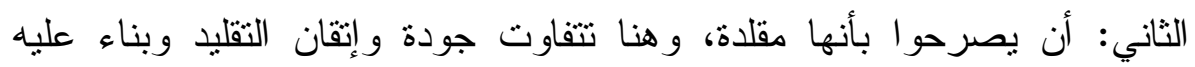
يتفاوت سعر السلعة.

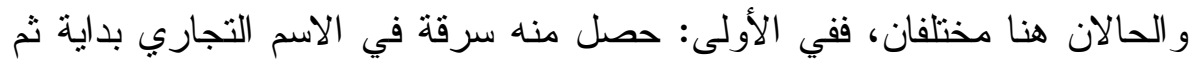

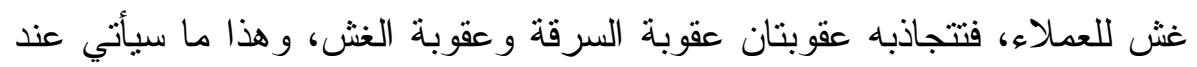
تفصيل عقوبة سرقة الحقوق المعنوية.

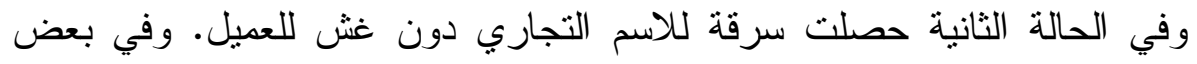
الحالات تحصل المعامل المقلدة على بعض التسهيلات من الثركة الأم أو الأصل

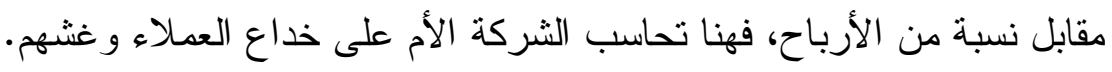

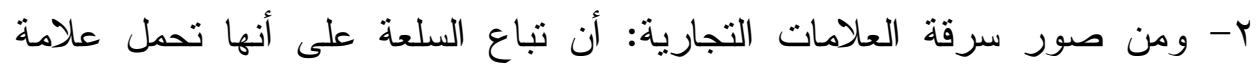

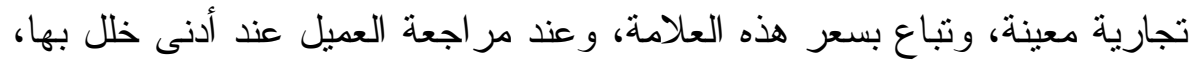

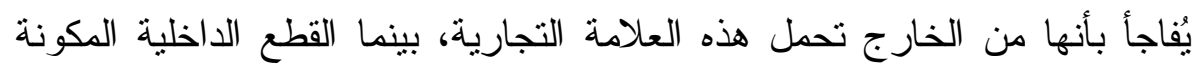
لهذه السلعة لا تمثل هذه العلامة. 
r- ومن صور سرقة الاسم التجاري، أن توجد محلات مشتهرة باسم تجاري معين،

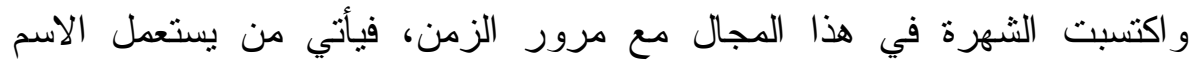

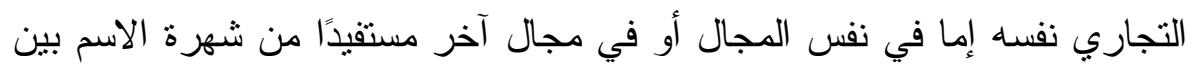

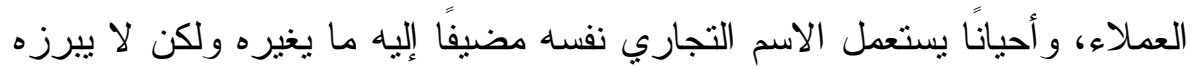

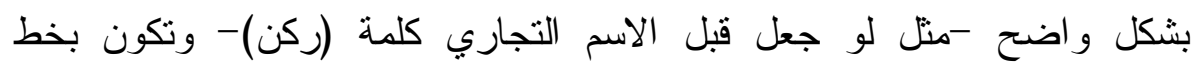

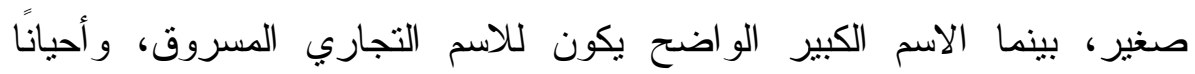

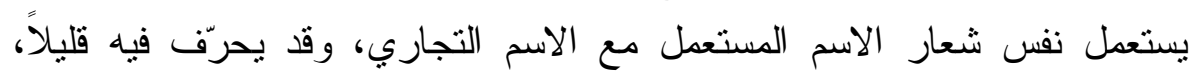
ولكن الر ائي لأول مرة لا يجد اختعلافًا كبيرًا.

المطلب الثالث: السرقة الإكترونية وقد تدخل هذه الصورة ضمن السرقات الو اردة على حقوق التأليف و الاختر اع، ولكن أفردته بمطلب خاص وذللك لكثرة انتشاره وظهوره، ومن هذه الصور :

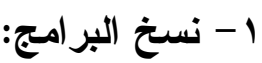

$$
\text { ولها صور منها: }
$$

1- عمل صورة (نسخة) من البرنامج الأصلي بواسطة قارئ وناسخ للأقر اص مناص الممغنطة دون إذن من مصدر البرنامج الأصلي. r- وضع نسخ من البرنامج الأصلي على عدة أجهزة فيتم تشغيل برنامج واحد على عدة الأهن أجهزة.

ץ- عمل نسخ كثيرة من البرنامج الأصلي بواسطة القارئ أو الناسخ الآلي دون إذن من مصدر البرنامج الأصلي وبيعها و المتاجرة فيها.

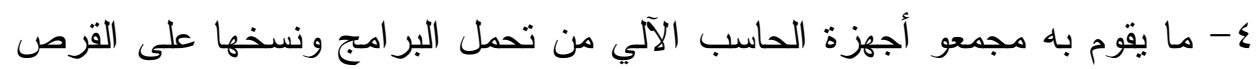
الصلب في كل جهاز ينت تجميعه.

و هذا معلوم خطره على البرنامج و على مستخدمي البرنامج، حيث لئ إن هذا

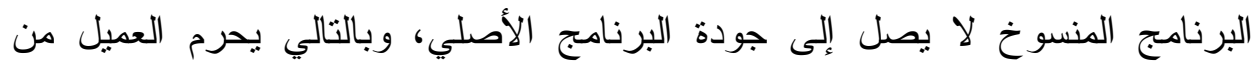

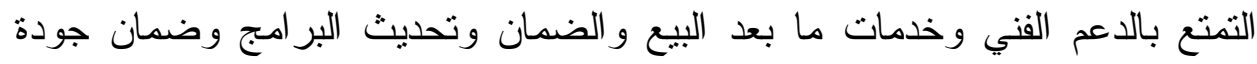

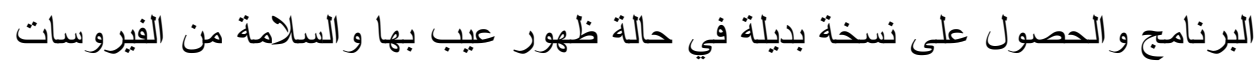
التي غالبًا ما تكون في البرامج المنسوخة والحصول على التدريب اللازم لاستخدام البر امج من بعض منتجي الر امج الأصلية. 
وكذلك فإن فيه ضرر على صاحب البرنامج حيث بذل جهدًا كبيرًا في إعداد مؤلفه

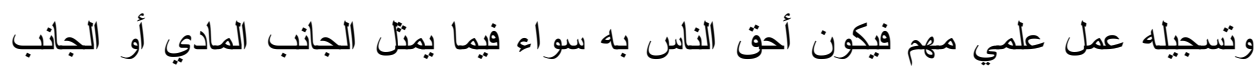
الأدبي.

ومن ثم فإن هذا يقلل الإنتاج الأصلي؛ لأن أصحابها قد اجتهدوا وبذلوا جهدًا

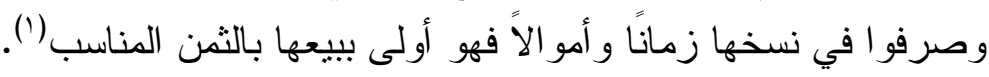
r - من صور السرقات الإكترونية.

ما يكون على شبكة الإنترنت ولها صور كثثرة، أعرض لصورة الإهورة واحدة منها وهي التصيد:

التصيّّ: هو شكل من أشكال السلوك الإجر امي الذي يشكل التهديدات المنز ايدة على مستخدمي الثبكة و المؤسسات المالية و التجارية، حيث يقوم المتصبدون بإرسال رسائل إلكترونية زائفة تطلب من مستخدمي الثبكة زيارة أحد المواقع الإكترونية

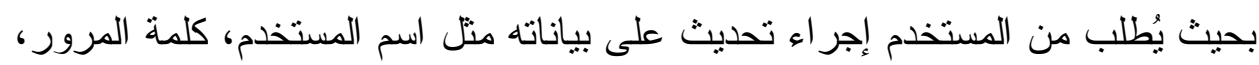
بطاقة الائتمان، الضمان الاجتماعي، رقم الحساب في البنك، هذه المواقع الإكترونية ز ائفة صممت فقط لسرقة معلومات المستخدم.

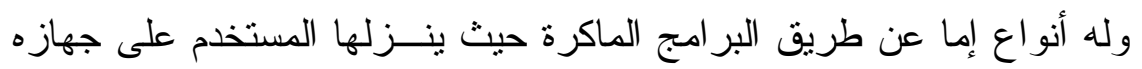

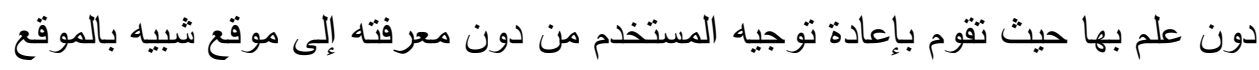
الذي يريد الدخول عليه ويقوم بجمع المعلومات الخاصة التي يدخلها المستخدم. وكذلك عن طريق (الباب الخلفي) حيث يقوم هذا البرنامج بإعطاء المتصيد

منفذا إلى جهاز المستخدم ليقوم عن طريق هذا المنفذ بالدخول إلى بيانات المستخدم.

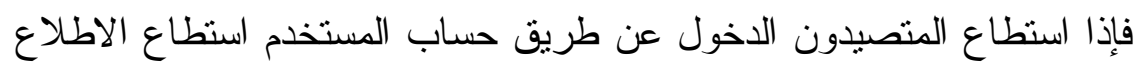

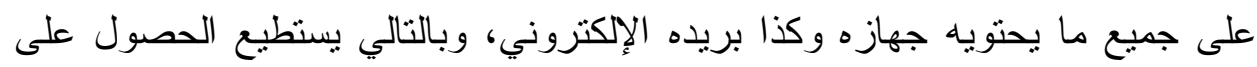

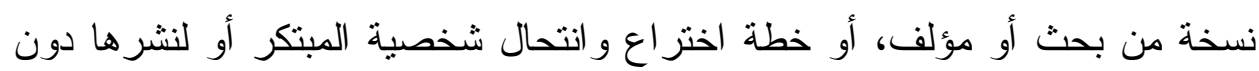
إذن المبتكر ، ولذلك إجر اءات وقائية منها:

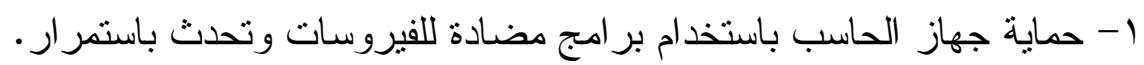
r- التأكد من تحديث متصفح الإنترنت. r- التأكد من استخدام موقع إلكتروني آمن في حال إدخال معلومات خاصة. 
ع - الحذر من الروابط في الرسائل الإلكترونية والتي تقود إلى صفحات إلكترونية.

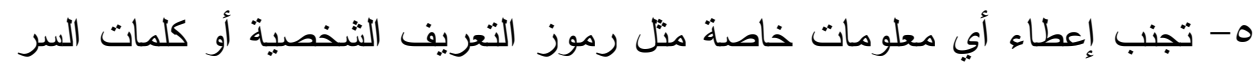

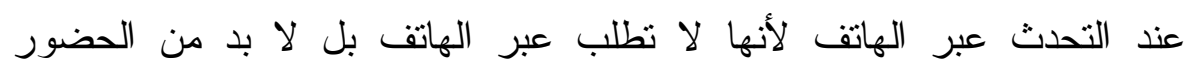
الثخصي (') r- ومن صور السرقات الإكترونية.

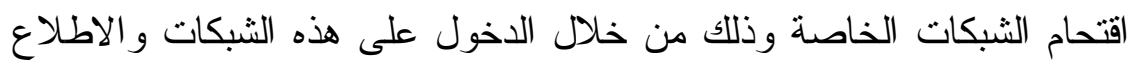
على ما يخص صاحب الثبكة من مواقع أو نتاج فكري أو علمي أو صور شخصية

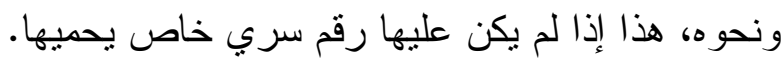
وفي حال وجود الرقم السري فتكون هنالك عملية (فلك الثفرة) لهذا الرقم ومن وند ثم الدخول، ومن المعلوم أن صاحب هذه الثبكة قد دفع مبلغًا مقابل هذه الخدمة، فدخول هند

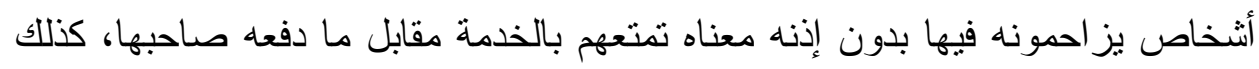
الضغط على الثبكة نتيجة مز احمتهم له عليها. أيضًا من خلال الدخول على شبكته الخاصة يمكنهم من الاطلاع على هلى نتاجه

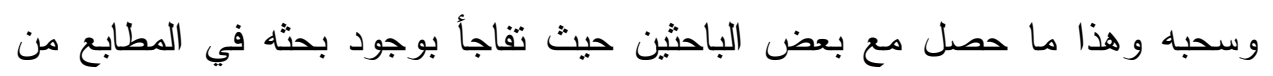
خلا اقتحام بعض القر اصنة لثبكته وسرقة نتاجه. 
المبحث الخامس

\section{وفيه مطلبان:}

المطلب الأول: الجهود التي تسهم في حماية الحقوق المعنوية قبل الاعتداء عليها

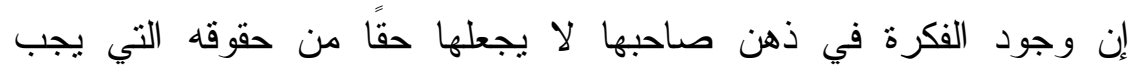
حمايتها؛ و إنما يعتبر الشخص مبتكرًا لله حق في ابتكاره إذا نشره منسوبًا إلبه ما لم يقم دليل على نفيه، وطرق نشره وتسجيله محفوظة في دواوين الدولة، وكل له مجال بخصها.

ومن هنا شرعت الدول لحماية الحقوق المعنوية على مستوى العالم فعقدت الاتفاقيات الدولية أواخر القرن التاسع عشر الميلادي لجعل العالم سوقًا تجاريًا واحدًا تسري عليه أحكام حماية الحقوق المعنوية، منها اتفاقيات بيرن لحماية الملكية الفنية

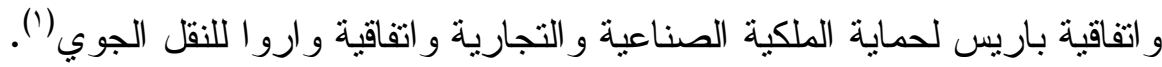

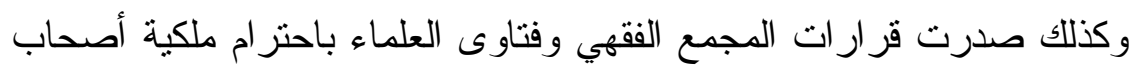
هذه الحقوق، ومن ذلك قرار المجمع الفقهي لرابطة العالم الإسلامي حول الاختراع:

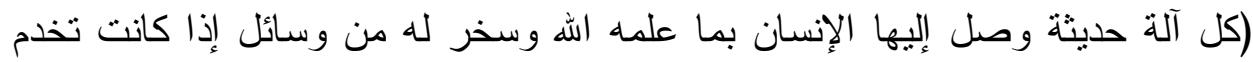

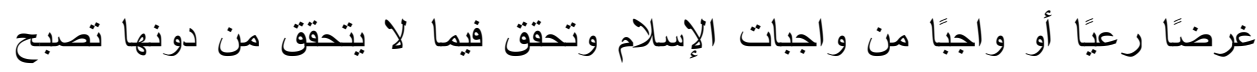
مطلوبة بقر درجة الأمر الذي تخدمه وتحققه من المطالب الثرعية وفية وفقًا للقاعدة الأصولية المعروفة (إن ما يتوقف عليه الو اجب فهو و اجب الابل).

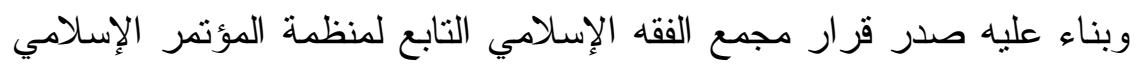

أو لاً: الاسم التجاري والعنوان التجاري و العلامة التجارية و التأليف و الاختر اع هي

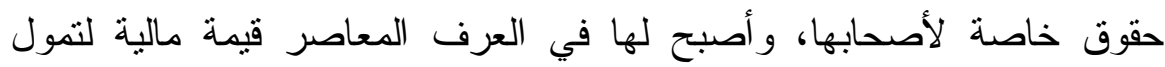

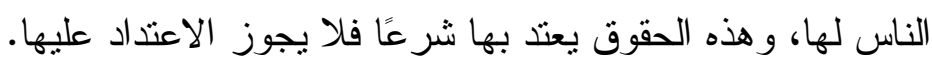

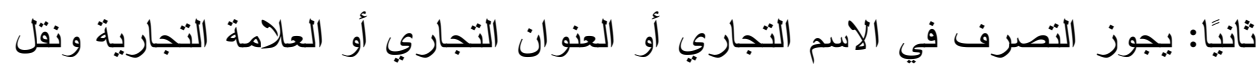
أي منها بعوض مالي إذا انتفى الضرر و التدليس والغش باعتبار أن ذلك أصبح حقًا ماليًا. 
ثالثًا: حقوق التأليف والاختر اع مصونة شرعًا و لأصحابها حق التصرف فيها و لا يجوز

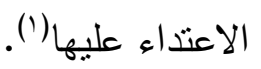

وكللك صدرت المر اسم الملكية بالمو افقة على امتلالك الاسم التجاري والعلامة

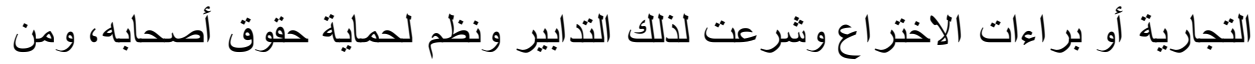

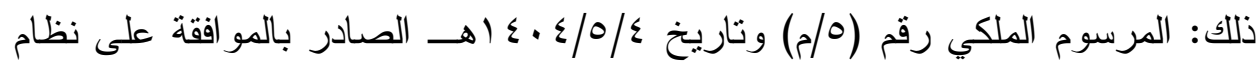

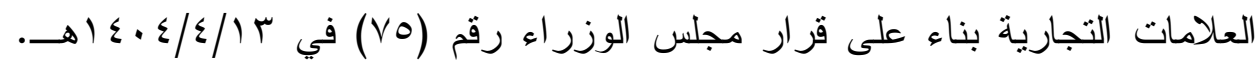
وتضمن: 1- ب تعريف العلامة التجارية. r- ما لا يعتبر علامة تجارية وذلك بتحديد الأشياء التي يجوز تسجيلها كعلامة تجارية. ب- من يملك تسجيل العلامات التجارية. ع - نتائج تسجيل العلامة التجارية، ومنها: أ- استعمال العلامة على المنتجات و الخدمات التي يقوم بها مالكها. ب- منع الغير من استعمالها أو استعمال أي علامة مشابهة. ج - ملكية العلامة وحق التصرف فيها بالبيع أو الرهن أو الترخيص للغير ابنهاه باستعمالها.

ه- إجر اءات تسجيل العلامة التجارية. 7- رخصة العلامة من قبل إدارة العلامات التجارية. V - الاعتر اض على تسجيل العلامة التجارية. كل هذه الاحتياطات و التدابير من أجل حفظ حق صاحبة العبة العلامة أو الاسم أو

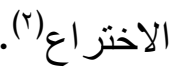
كذلك هنالك مجهودات تبذل من قبل الجهات المسؤولة لحماية الحقوق المعنوية قبل الاعتداء عليها، منها: 1- إعداد المطويات و اللوحات الإرشادية والكتيات التي تعنى بنطبيق نظام حماية حقوق المؤلف. 
r- ترتيب حملات إعلامية تقوم بنشر الوعي بالحقوق المعنوية وما تشمله هذه الحقوق وحرمة التعدي عليها.

ب- القيام بجو لات تقتيشية على المنشآت و المحلات و المؤسسات و الثركات بأنو اعها وضبط المخالفات.

ع- تتفذ الجهات المسؤولة حملات تفتيش ورقابة على المنافذ الحدودية وضبط المخالفات (') ه- ثقوم الجهات المسؤولة عند تسجيل الاسم التجاري أو العلامة التجارية بالتأكد من

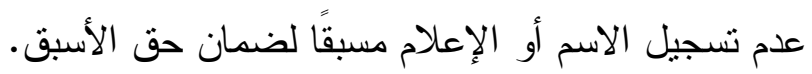
צ- توفير الخدمات المميزة لمن يشتري النسخة الأصلية كالضمان، وتحديث الإنيثن لبرنامج

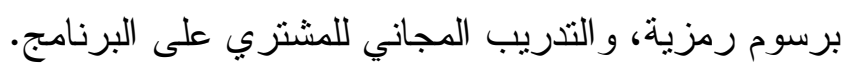
V- وضع نسخ من المصنف في المكتبات العامة أو دور المحفوظات للاحتفاظ به ليه كإثبات نسبته للمصنف إلى من مؤلفه.

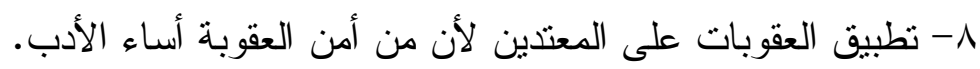

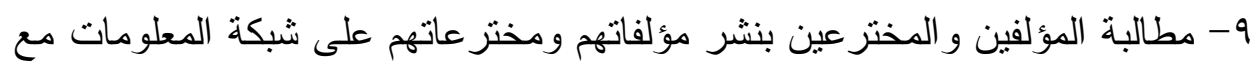

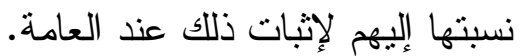

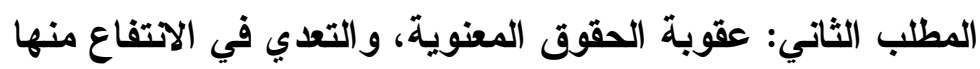

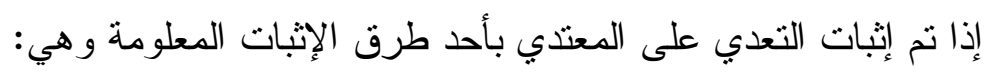

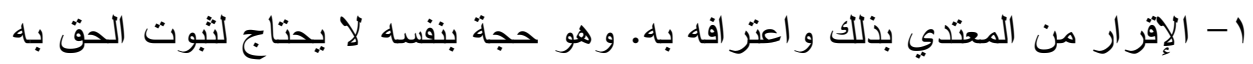
إلى القضاء فهو أقوى ما يُحكم به و هو مقدم على البينة. r- ثبوت تعديه بالثهادة. ويقبل فيها عدلان. ب- ثبوت تعديه باليمين عند عدم البينة.

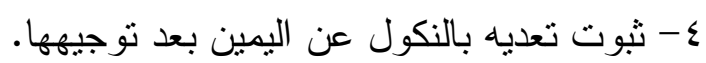
0- ثبوت تعديه بالقر ائن.

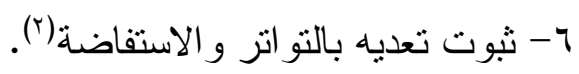
فإن الاعتداء بالسرقة لا تخلو من حالين: 
الأولى: أن يكون التعدي بالسرقة واقع على عين المؤلف، أو الاختز اع ونحوها فإنها تعتبر سرقة منو افرة الثروط وتطبق فيها العقوبة الحدية وهي قطع اليد؛ لقوله

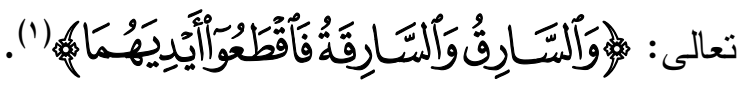

$$
\text { وهذا لا خلاف بين العلماء كرحمه الله - فيه. }
$$

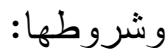

1- أخذ مال معصوم خفية.

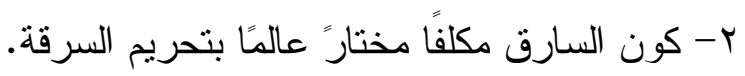
ب- كون المسروق مالاً محترمًا. ع - انتفاء الثبهة. 0- انتفاء الثبهة.

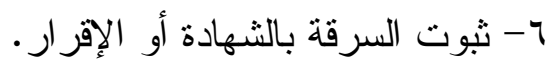
V- أن يكون المال مسروقًا من حرز مثلثه.

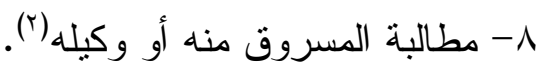

لكن إذا كانت المؤلفات في علم شرعي ففي وجوبه واله القطع بسرقتها خلاف مبني على الخلاف في جو از المعاوضة عليها، و الجمهور من المالكية و الثافعية و الحنابلة و أبويوسف من الحنفية(؟) يرون جو از أخذ العوض عليها لما تقدم من الأدلة، وبناء عليه

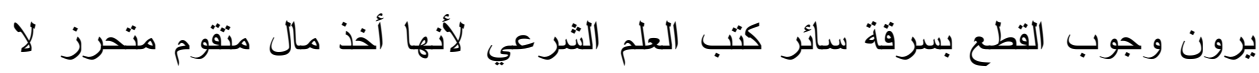

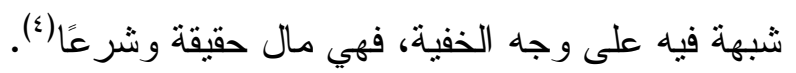

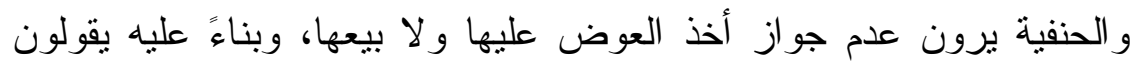

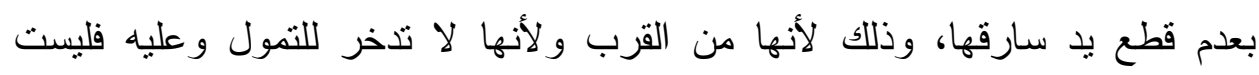
بمال (0).

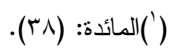

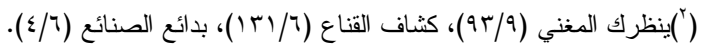

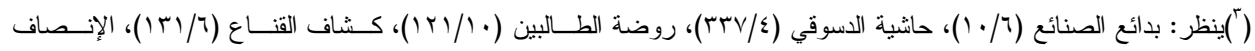

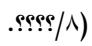


و الر اجح هو قول الجمهور، و عمومًا فهذه ليست من السرقات المعنوية التي هي موضع البحث.

الثانية: سرقة الحقوق الواردة على هذه المصنفات والمخترعات.

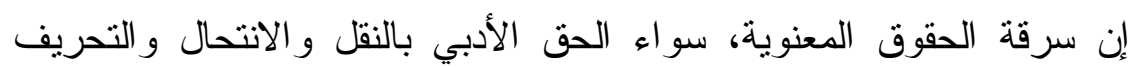

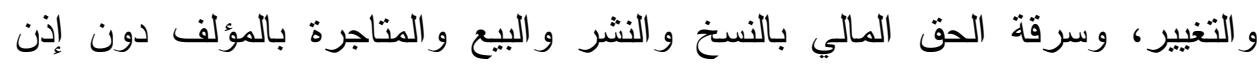

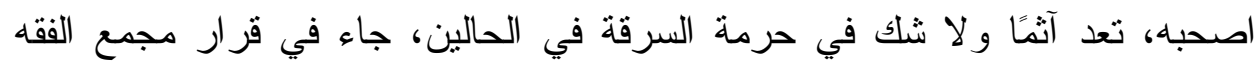

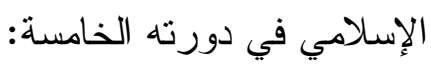
(قرار رقم (0) بشأن [الحقوق المعنوية] إن مجلس مجمع الفقه الإسلامي المنعقد

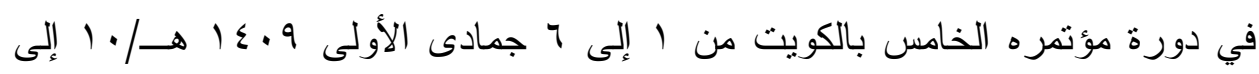
10 بعد اطلاعه على البحوث المقدمة من الأعضاء و الخبراء في موضوع (الحقوق

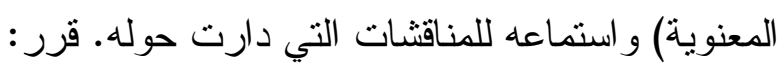

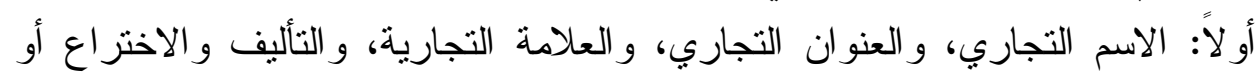

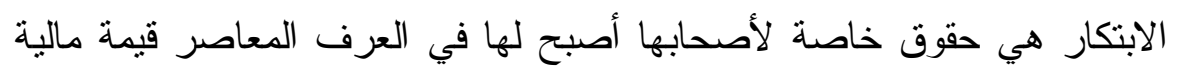

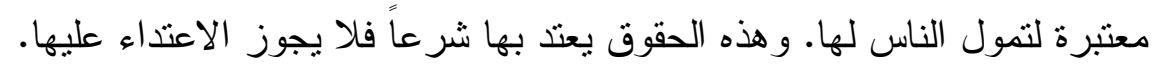

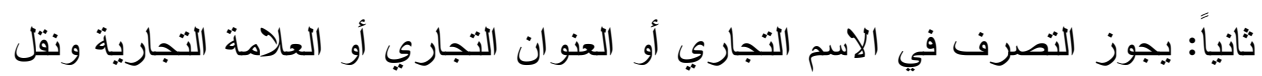

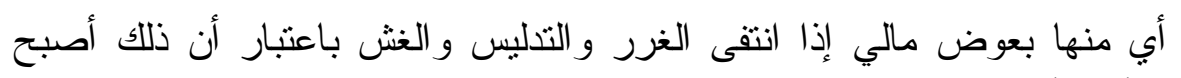
حقاً مالياً.

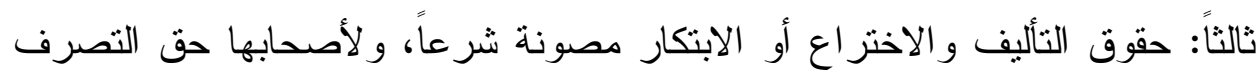

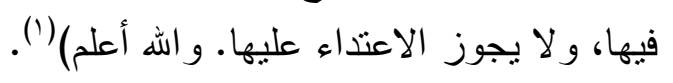

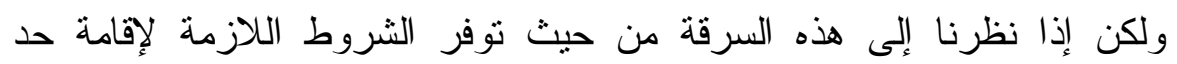

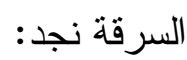

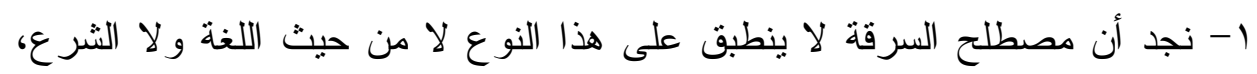

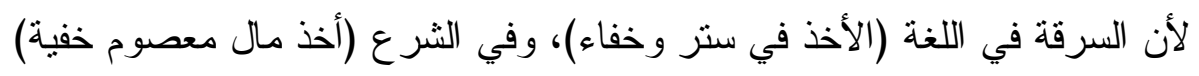

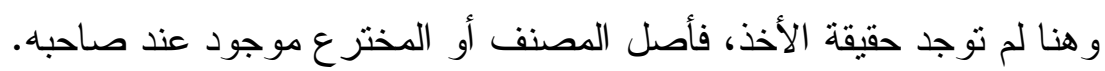


ץ- أن الأخذ على وجه الخفية والاستتار، وهذا لا يُخفى بل يعلن وينشر في المواقع ودور النشر - ون

ץ- وجود الثبهة، وذلك أن هذه المؤلفات و المخترعات يرد عليه حقان حق خاص،

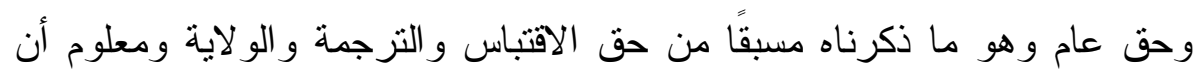
الحدود تزدء بالثبهات.

فإذا ثبت ذلك فالذي يظهر - وو اله أعلم- أن هذه لا تسمى سرقات بالمصطلح

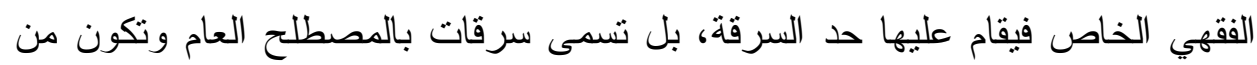

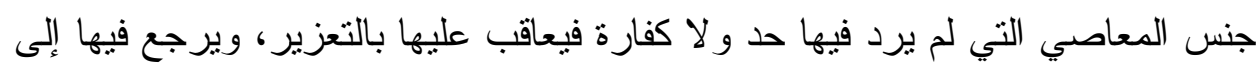
رأي الحاكم في كل حادثة بحسبها. يقول الثيخ د/ نصر فريد واصل -مفتي جمهورية مصر العربية سابقًا-: (أن من يقوم بهذه السرفة فإنه يخضع لعقوبة التعزير حسب ما يقرره القاضي وحسب الحال

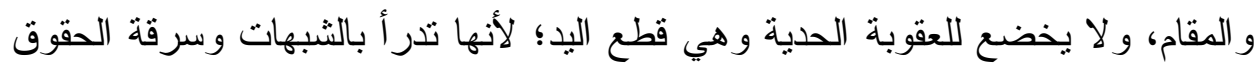

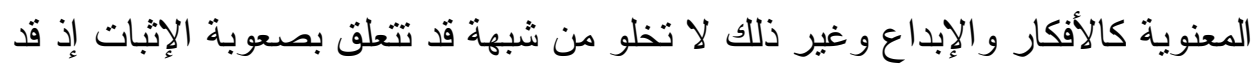

يتو افق الفكر و الإبداع لدى أكثز من شخص فيصعب تحديد صاحب الفكر و الإبداع)(').

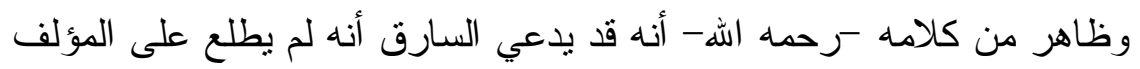

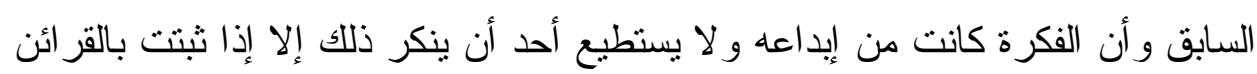
السابق ذكر ها في طرق إثبات التعدي. ولكن مع ذلك حتى لو ثبتت سرقته ولو بأعلى درجات طرق إثبات التعدي،

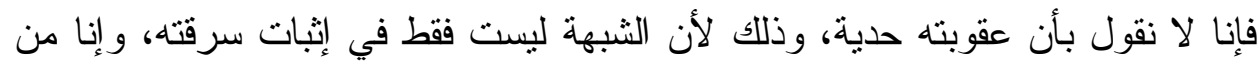
حيث ورود الحق العام عليها. يقول د/ حسين الثهر اني: (إن هذه الحقوق حق لأصحابها ومقتضى ثبوت هذه

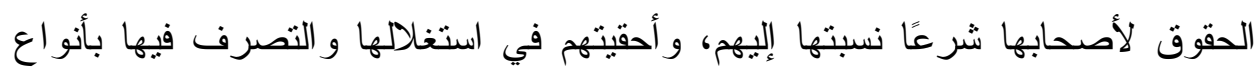
التصرفات المباحة، ولا يجوز الاعتداء عليها، فإذا ثبت هذا فمتى نم الاعتداء عليها

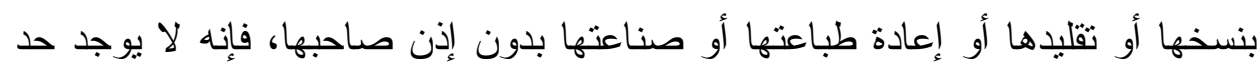
القطع لعدم ثو افر شروط القطع المعتبرة شرعًا إلا إذا سرق أصل الكتاب أو الآلة

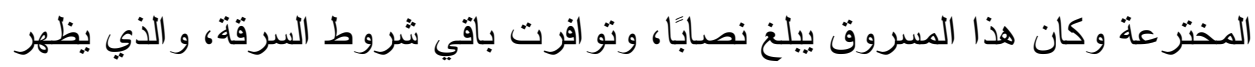


أن العقوبة المناسبة للاعتداء على حقوق الاختزاع و التأليف هي العقوبة بالتعزير ومرجعها إلى تقدير القاضي ('). وبالتالي يرجع تعبين نوع العقوبة التعزيرية ومقدارها إلى اجتهاد الحاكم

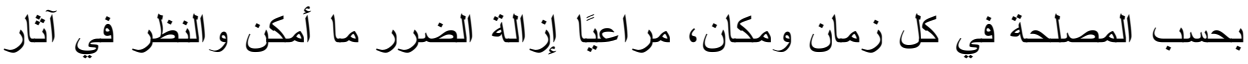

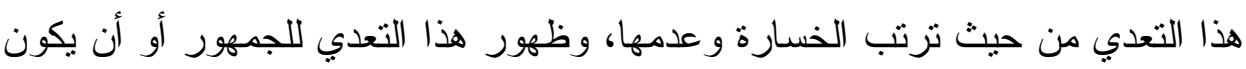
على المستوى الفردي. كذلك تكر ار التعدي وتغليظ العقوبة على المعتدي وكذللك تفتي وني هذا الأمر في المجتمع و انتشاره. وقد جاء الثرع بعقوبات تعزيرية متتوعة(؟)، وهي: في البدن بالجلد و القتل، التهاره

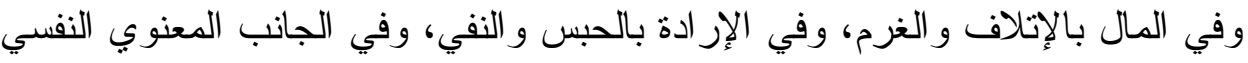

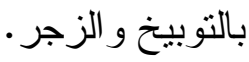
* الغز امات المالية: مثنال ذلك في حال نسخ البرامج و استير ادها، فإنها تسحب من

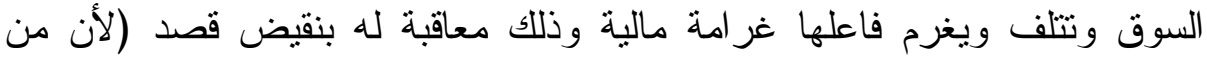

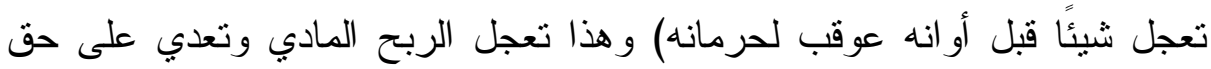
صاحب الحق المالي فيعاقب بالغر امة المالية. كذلك يقال في كل من تعدى على على أحد الرد هذه الحقوق بقصد المال. * الإتلاف والسحب من الأسواق: وذللك في كل البضائع التي تحمل اسمًا تجاريًا مغشوشًا، أو في الكتب التي نشرت، وقد حصل فيها تغيير دون إذن صاحبها أو الون

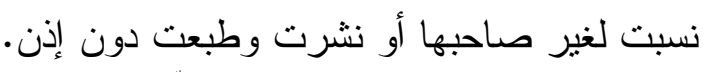
* التشهير: وذلك إذا دعى نسبة المؤلِّ إليه من أجل الثهرة ونثاء الناس ومدحهم فيعاقب بنقيض قصده وذذلك بأن يشهر به بين الناس.

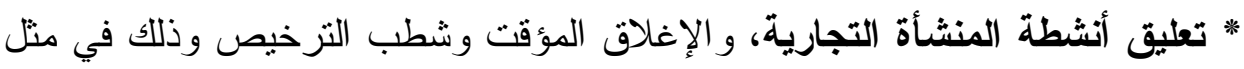

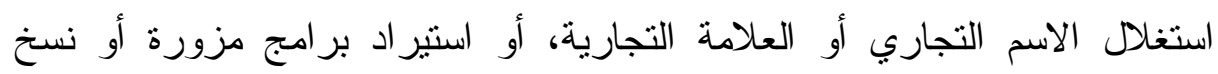
مزورة فيعاقب بهذه العقوبات. فإن تكرر منه هذا الفعل فيغلق المحل نهائيًا ويعلن بهن ذلك للملأ. 
* السجن: وذلك إذا تكرر التعدي و أصبح صفة ملازمة للشخص فلا بد من حبسه حتى يتأدب ويكف شره، وهذا فيه تشديد للعقوبة وهو مشروع في الدين. * تعويض المعتدى على حقه من قبل المعتدي بما لديه من مواهب و ابتكار ات، وذللك

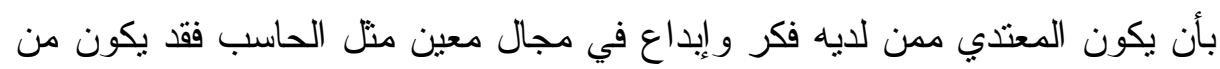

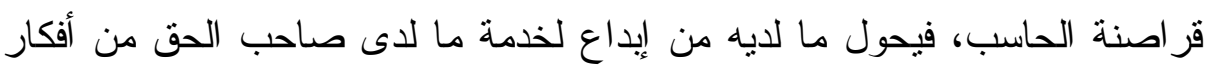

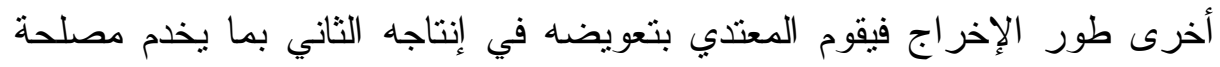

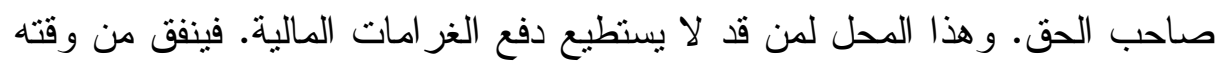
وجهذه لتعويض صاحب الحق. * تعزيزات القذف: وقد تكون هذه العقوبات منحصرة في الجلد ولعله يُتصور وقوعها فيما لو غير محتوى الكتاب بما قد يسيء للمؤلف في شخصه أو أو خلقه وينظر فيها لقصد السارق.

* الوعظ والزجر والتوبيخ والتأنيب: وهذا يكون في حق من لم يسبق منهم هذا الفعل،

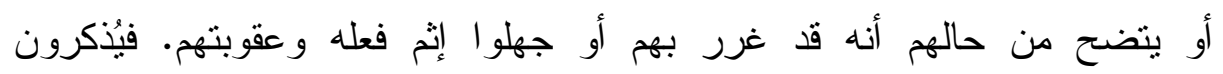
ويُو عظون.

* الحرمان من ممارسة بعض الحقوق لبعض الوقت، منت لو كان مؤلف فإنه يحرم

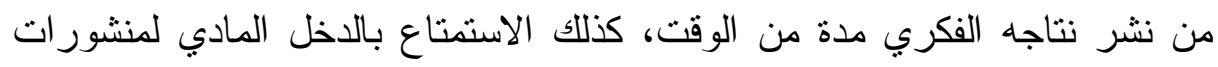

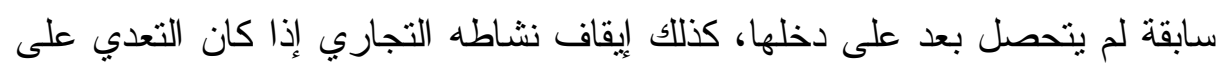
الاسم التجاري أو العلامة التجارية وهكذا. 
الحمد لله على التمام و التيسير، وفيما يلي بيان أبرز النتائج التي توصلت إلبها من

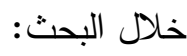

$$
\text { - تعريف السرق التي يترتب عليها حد القطع. }
$$

- المر اد بالحقوق المعنوية وهو : سلطة الشخص على على شيء غئ عير مادي مو اد أكان نتاجًا ذهنيًا،

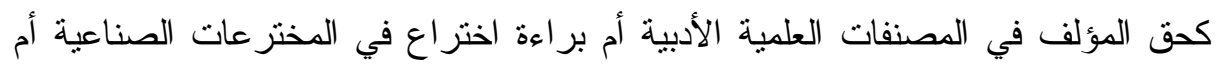
ثمرة لنشاط تجاري يقوم به التاجر لجلب العلماء. - ركنا الحق الأدبي والفرق بينهما، وهي الحق الأدبي ويشمل النسبة و الإذن بالنشر و السمعة

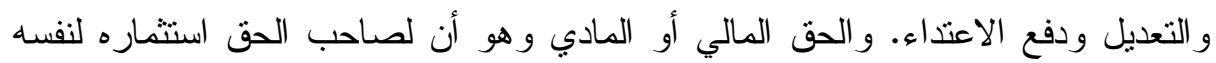
و السماح لغيره باسنتمار ه. - المرجع في اعتبار الحقوق المعنوية هو العرف والقاره المصلحة المرسلة. - وقت اعتبار الحق المعنوي ومرجعيته إلى العرف و والمقوف المصلحة المرسلة.

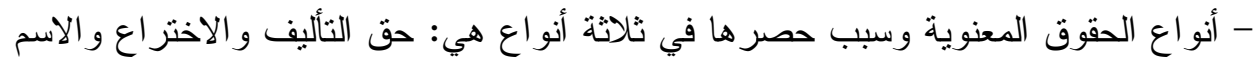

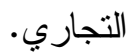

- حق التأليف: هو ما يثبت للعالم أو المؤلف من اختصاص شرعي بمؤلفه بمكنه من نسبته

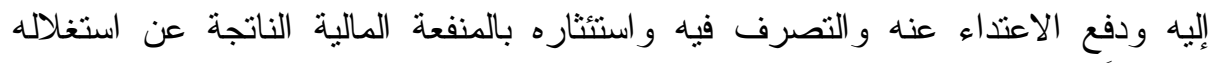

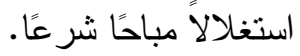
- حق الاختر اع: و هو ما يثبت للمخترع من اختصاص شاص شرعي بمختر عه يمكن من نسبته إليه

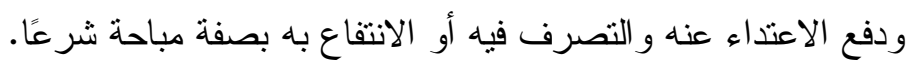
- حق الاسم التجاري: وأنه بطلق وير اد به مصطلح الأنين:

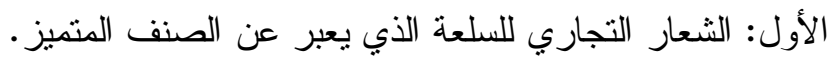
الثاني: اسم المحل التجاري المعلن عليه.

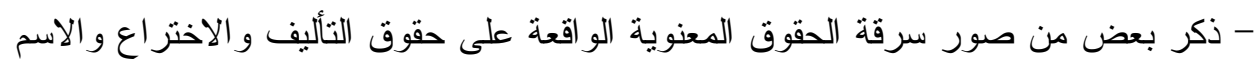
التجاري وعن طريق شبكة المعلومات.

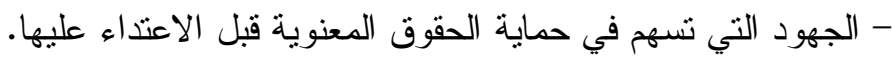

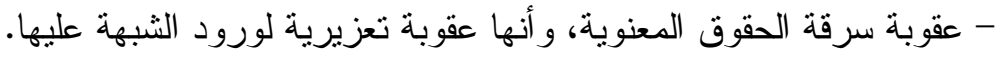

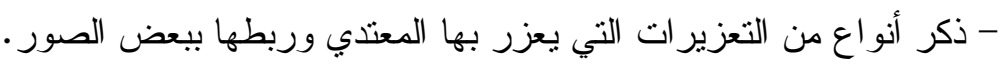

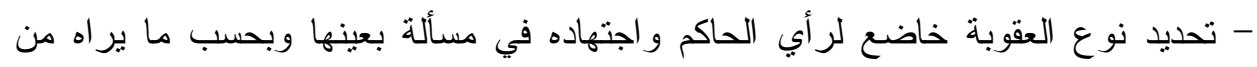
الأحو ال باختلاف الزمان و المكان. هذا واله أعلم وصلى الله وسلم وبارك على خير الأنام محمد بن عبداله. 


\section{ثبت المصادر و المر اجع}

- - الأحكام الفقهية للتعاملات الإككترونية، عبدالرحمن بن عبداله السند، دار الوراق، دار

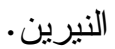

- - الأشباه و النظائر، عبدالرحمن ابن أبي بكر السيوطي، دار الكتب العلمية، ب.؛ (هـ،

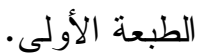

- - إعلام الموقعين عن رب العالمين، أبوعبداله محمد بن أبي بكر بن أبي أيوب المعروف تهمة (بابن قيم الجوزية)، تحقيق: عبدالرحمن الوكيل، مكتبة ابن تيمية.

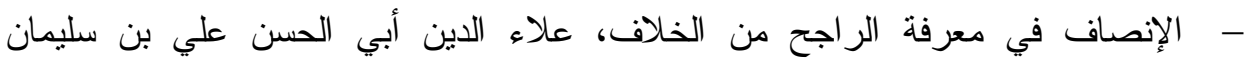
المرداوي، دار إحياء التراث العربي. - أهم أثنكال مخالفات استخدام بر امج الحاسب الآلي التي يعاقب عليها النظام، مطوية تصدر عن الإدارة العامة لحقوق المؤلف، وزارة الثقافة والإعلام بالمملكة العربية السعودية. - - البحر الرائق شح كنـز الدقائق، زين الدين ابن نجيم الحنفي، دار المعرفة، بيروت، الطبعة الثانية. - - بحوث في فقه المعاملات المالية المعاصرة، د/ علي محيي الدين علي القره و انمي، دار

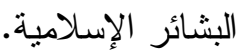
- - بدائع الصنائع في ترنيب الثرائع، علاء الدين الكاساني، دار الكتاب العربي، بيروت،

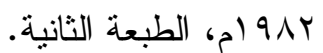
- - بدائع الصنائع في نرتيب الثرائع، علاء الدين أبوبكر بن سعود بن أحمد الكاساني، دار الكتب العلمية، بيروت، لبنان. - - بداية المجتهد نهاية المقتصد، لابن رشد محمد بن أحمد بن محمد، دار الكتب الإسلامية. - - بيع الاسم التجاري و الترخيص، حسن عبداله الأمين عن مجلة مجمع الفقه الإسلامي. - - بيع الاسم التجاري و الترخيص، د/ و هبة الزحيلي، عن مجلة مجمع الفقه الإسلامي.

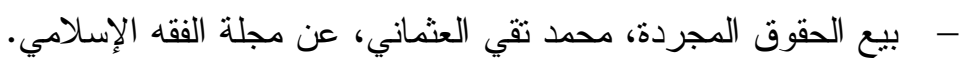
- تاج العروس من جواهر القاموس، محمد مرتضى الحسيني الزبيدي، دار الهداية. - ت تبيين الحقائق شرح كنــز الرقائق، فخر الدين عثمان بن علي الزيلعي، دار الكتب العلمية.

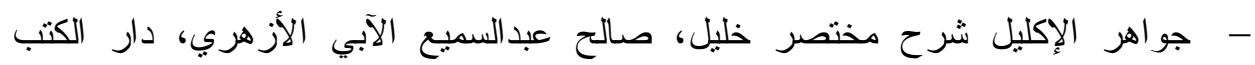

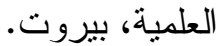


- - ماثية ابن عابدين، المسماة (رد المحتار على الدر المختار، شرح تتوير الأبصار) لمحمد بن أمين الثهير (بابن عابدين)، دار الكتب العلمبة. - حاثنية الدسوفي على الثرح الكبير، محمد عرفة الدسوقي، دار الفكر، بيروت، تحقيق محمد عليش. - - الحاوي الكبير، علي بن محمد الماوردي البصري، دار الكتب العلمية، بيروت. - - - حق الابتكار في الفقه المقارن د/ فتحي الدريني مؤسسة الرسالة.

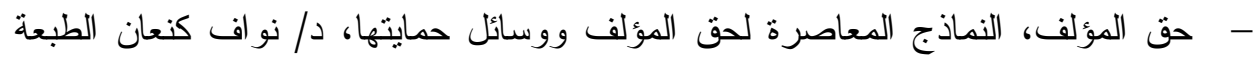
الأولى، V. - - حقوق الاختراع والتأليف في الفقه الإسلامي، حسين بن معلوي الشهر اني، دار طيبة،

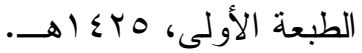
- - الحقوق المعنوية (حق الإبداع العلمي، حق الاسم التجاري) طبيعتها وحكم شرائها، د/ محمد سعيد البوطي. - الحقوق المعنوية (حق الإبداع وحق الاسم التجاري)، محمد سعيد رمضان، عن مجلة مجمع الفقه الإسلامي. - - الحقوق المعنوية، د/ محمد سعيد رمضان البوطي، مجلة مجمع الفقه الإسلامي.

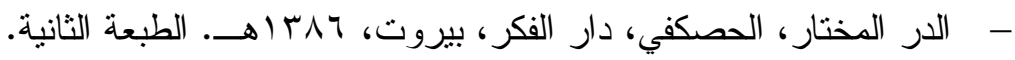

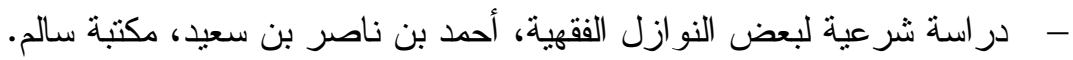
- - الذخيرة، شهاب الدين أحمد بن إدريس القر افي، دار الغرب الإسلامي. - روضة الطالبين وعمدة المفتين، يحيى بن شرف النووي، الكتب الإسلامي، بيروت، الإسي، 0. أهـ، الطبعة الثانية.

- - شرح الخرشي، محمد بن عبداله بن علي الخرشي المالكي، دار الكتب العلمية، بيروت.

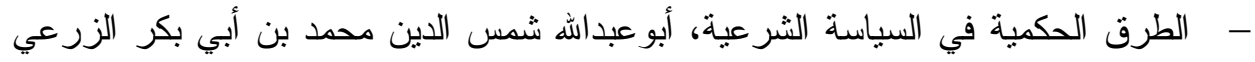
الدمثقي، مطبعة المدني، تحقيق: د/ محمد جميل غازي.

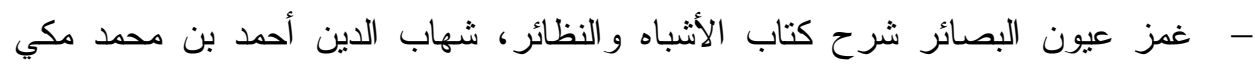

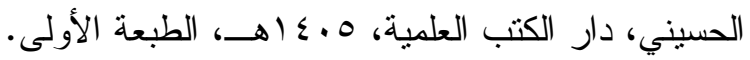
- - فتح الباري، أحمد بن علي بن حجر العسقلاني، دار المعرفة، بيروت، المكتبة التجارية. 
- فتح القدير، كمال الدين محمد بن عبدالواحد السيواسي ثم السكندري المعروف (بابن الهمام) مع نكملته (نتائج الأفكار في كثف الرموز والأسرار) (شمس الدين أحمد بن

$$
\text { قودر) دار الكتب العلمية. }
$$

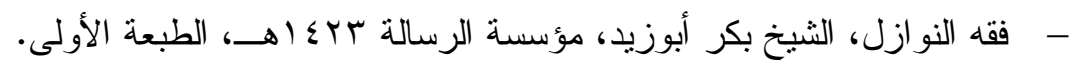

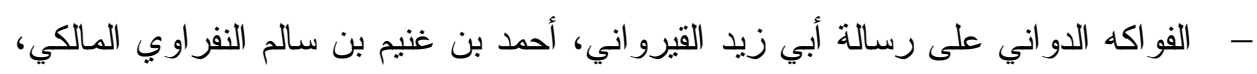
دار الفكر، بيروت.

- - - القاموس المحيط، محمد بن بعقوب الفيروز آبادي، دار المعرفة، بيروت.

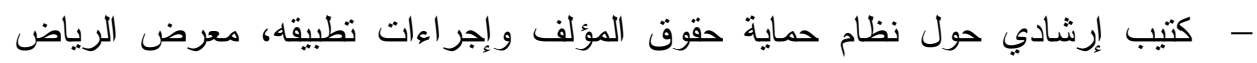

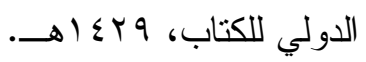

- - كثاف القناع عن منت لإقناع، منصور بن إدريس البهوتي، المكتبة التجارية، مكة.

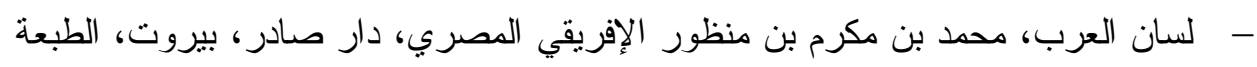
الأولى.

- - المبسوط، شمس الدين السرخسي، دار المعرفة، بيروت. - مجلة مجمع الفقه الإسلامي، المنبثق من منظمة المؤتمر الإسلامي، جدة، دئ.

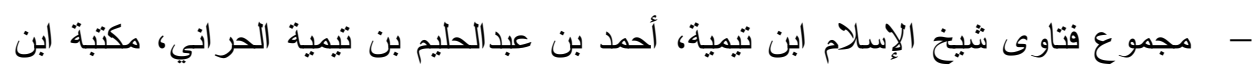

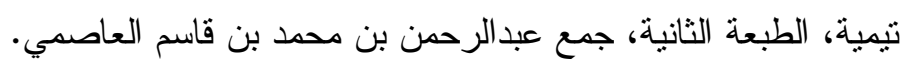

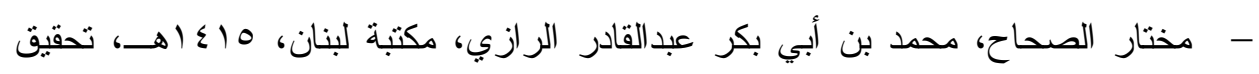
محمود خاطر . مختر لمخ - - المدخل على نظرية الالتز ام العامة في الفقه الإسلامي، مصطفى أحدد الزرقا، دار القلم،

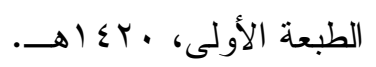

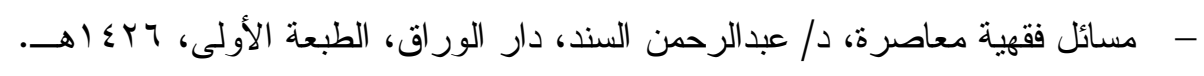

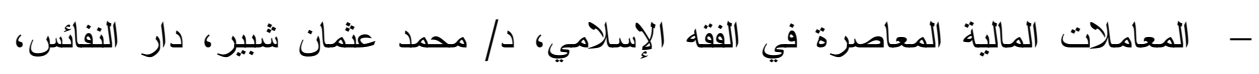

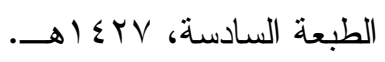

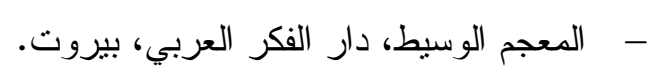

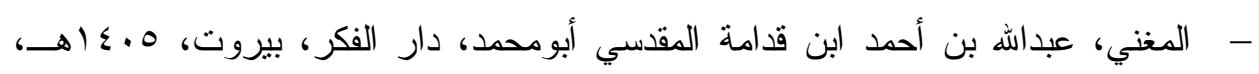

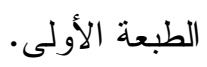


- مغني المحتاج على معرفة ألفاظ المنهاج، شمس الدين محمد بن الخطيب الثربيني، دار الفكر

- - المغني، موفق الدين عبداله بن أحمد المعروف بابن قدامة، دار إحياء التزاث العربي، بيروت.

- مقاييس اللغة، أبو الحسنأحد بن فارس بن زكريا، دار الجيل، بـأهـ، الطبعة الثانية، تحقيق: عبدالسلام محمد هارون.

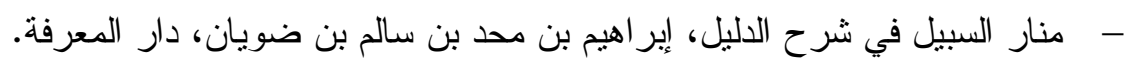

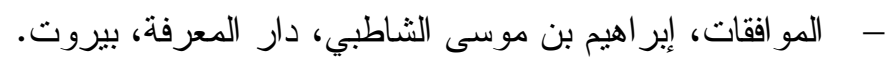

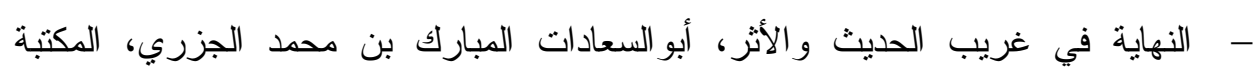
العلمية، بيروت.

- - الوسيط في شرح القانون المدني، للسنهوري عبدالر ازق بن أحمد، دار النهضة العربية. 
